The Impact of Motives-Related Feedback on Drinking to Cope Among College Students

Claire E. Blevins

Dissertation submitted to the faculty of the Virginia Polytechnic Institute and State University in partial fulfillment of the requirements for the degree of

\author{
Doctor of Philosophy \\ in \\ Psychology \\ Robert Stephens, Chair \\ George Clum \\ Thomas Ollendick \\ Jungmeen Kim-Spoon \\ Steven Lash
}

March 27, 2015
Blacksburg, VA

Key words: motives for substance use, alcohol, normative feedback, brief intervention 
MOTIVES-RELATED FEEDBACK AND DRINKING TO COPE

\title{
The Impact of Motives-Related Feedback on Drinking to Cope Among College Students \\ Claire E. Blevins
}

\begin{abstract}
Motives for alcohol use are associated with distinct antecedents and consequences.

Drinking alcohol to cope with negative affect is consistently associated with the most problematic patterns of use. Interventions targeting drinking to cope are needed. This randomized controlled treatment trial evaluated the impact of a brief coping motive feedback-based intervention on motives and problematic outcomes associated with drinking. In addition, a more comprehensive model of the antecedents and consequences of drinking to cope was tested. The study randomized 170 participants to receive either a brief Standard Feedback Condition (SFC; $\mathrm{n}=83$ ) or a Motives Feedback Condition $(\mathrm{MFC} ; \mathrm{n}=87)$ that added education and feedback on drinking to cope as well as alternate coping strategies. Significant reductions in drinking to cope with depression were greater in the MFC at the 2-month follow-up, but the intervention's effect on drinking to cope with anxiety did not reach conventional levels of statistical significance. Significant reductions in drinking and negative consequences were observed but did not differ significantly by condition. Change in coping with depression motives mediated the effect of the intervention on outcomes of drinking and negative consequences. Partial support was found for a structural model linking antecedents of use, coping motives, and consequences associated with substance use. This study is a promising new direction in motives research, providing support for brief interventions incorporating motives-related feedback and for furthering our understanding of the origins and consequences of drinking to cope with negative affect.
\end{abstract}




\section{Table of Contents}

Introduction.............................................................

Methods......................................................................

Participants......................................................6

Design........................................................6

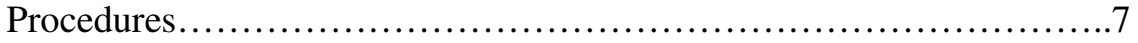

Measures........................................................

Results.............................................................. 12

Preliminary Analyses.............................................12

Goal 1: Coping-Based Motives Intervention......................13

Goal 2: Motivational Model of Alcohol Use.........................17

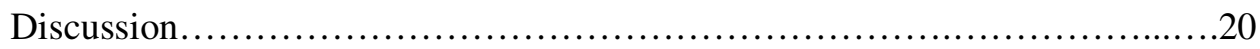

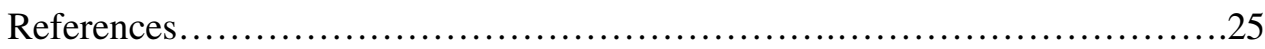

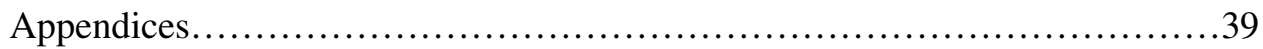

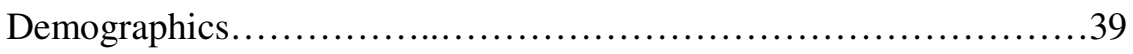

Motives for Alcohol Use........................................40

Risky Personality Profiles.....................................41

Situations of Use.................................................42

Drinking Companions and Locations............................43

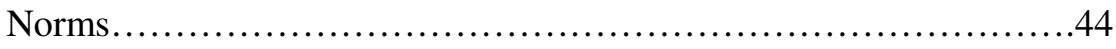

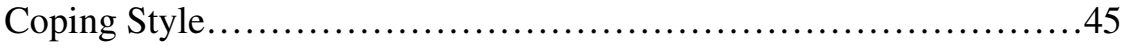

Expectancies of Use.........................................46

Stage of Change, Importance and Confidence Rulers.................47

Alcohol Use..................................................48

Other Drug Use............................................49

Alcohol Problems...............................................50 
MOTIVES-RELATED FEEDBACK AND DRINKING TO COPE

Manipulation Check............................................51

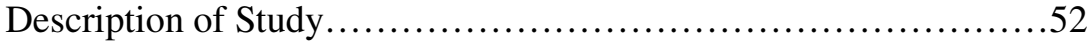

Verbal Consent for Screening and Screening Questions..............53

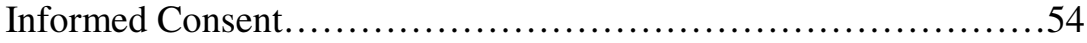

Standard Feedback Condition PFR ..............................57

Motives Feedback Condition PFR..............................60 


\section{MOTIVES-RELATED FEEDBACK AND DRINKING TO COPE}

\section{List of Figures}

Figure 1. Change in Quantity of Alcohol Use Over Time..................................

Figure 2. Change in Alcohol-Related Problems Over Time............................... 35

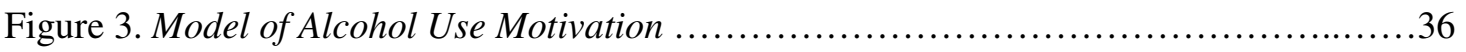

Figure 4. Analyses Testing the Mediational Value of Change in Coping Motives ................37

Figure 5. Structural Equation Modeling Results ........................................ 38 


\section{MOTIVES-RELATED FEEDBACK AND DRINKING TO COPE}

\section{List of Tables}

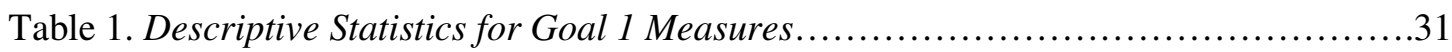

Table 2. Time by Condition Effects of the Motives-Based Intervention.........................

Table 3. Descriptive Statistics and Correlations for Goal 2 Measures........................33 
MOTIVES-RELATED FEEDBACK AND DRINKING TO COPE

\section{The Impact of Motives-Related Feedback on Drinking to Cope Among College Students}

Claire E. Blevins

Alcohol use is especially prevalent in young adulthood. Among college-aged individuals, $47 \%$ of $18-20$ year-olds and $70 \%$ of $21-25$ year-olds had used alcohol in the past month (Substance Abuse and Mental Heath Services Administration, 2012). Approximately $15.7 \%$ of individuals aged 18-25 meet diagnostic criteria for an alcohol use disorder. Due to the prevalence of use and potential consequences, there is a need to understand the mechanisms that may lead to problematic use.

Motives for use can provide insight into characteristics of users and outcomes associated with use. Based on the motivational model of alcohol use, the most commonly studied motives include coping with negative affect, conformity with others, enhancement of positive affect, and social experience (Cooper, 1994). Motives for substance use have been shown to predict distinct antecedents and consequences of use in a variety of studies and populations (e.g., Cooper, Russell, Skinner, \& Windle, 1992; Cooper, 1994). Using for the motive of coping with negative affect has received the most empirical attention and has been associated with theoretically related constructs such as negative affect, coping strategies, expectancies of the effects of use, situations in which a substance is typically consumed, rates of use, and negative consequences associated with use (Blevins \& Stephens, under review). The current study builds on current literature in two ways. First, it examines whether a brief intervention targeting drinkers who use to cope augments the impact of existing interventions. Second, it tests a more complete model of the theoretical relationships between using to cope and antecedents and consequences of alcohol use.

Preliminary evidence from treatment studies indicates that targeting motives may be useful in reducing problematic use and provides support for the importance of motives. For instance, Banes and colleagues found a change in motives for use following participation in a motivational enhancement and cognitive-behavioral treatment program for marijuana dependent 


\section{MOTIVES-RELATED FEEDBACK AND DRINKING TO COPE}

adults (Banes, Stephens, Blevins, Walker, \& Roffman, 2014). In particular, they reported associations between reductions in coping motives and reductions in negative outcomes, suggesting that motives for use may be a mechanism of change. Conrod and colleagues in a series of studies $(2000 ; 2006 ; 2011)$ showed that brief interventions matched to personality profiles of participants that were indicative of risk for substance use (i.e., anxiety sensitive (AS), hopeless-introverted $(\mathrm{H})$, sensation-seeking/impulsive $(\mathrm{SS})$ ) resulted in greater reductions in negative outcomes associated with use than mismatched interventions. Their intervention included feedback on personality, drinking norms, reasons for use, consequences of use, and coping skills. In the third study (2011) they showed that there were reductions in drinking motives consistent with the personality-targets of the interventions. LaBrie and colleagues (2008) studied the effect of a brief motivational enhancement intervention that provided motives information. Results indicated that interventions that discussed motives for use were associated with significant reductions in use and consequences as compared to intervention that did not include motives information. Their intervention did not target specific motives nor did it provide specific feedback on the individual's motives for use but rather provided education on motives.

Despite the work that has established that motives for use are associated with rates of use and consequences, no known treatment study has utilized a brief intervention format to target specific motives directly. The Conrod studies utilized coping strategies specific to each personality profile, which the current study also utilizes specifically for coping motives for use. However, the current study provides the motives-specific coping strategies in the context of a brief intervention. The LaBrie (2008) study utilized motives information in a brief format, but did not provide specific feedback based on the motives that the individual specifically endorsed. Thus, this treatment intervention expands what is known about motive-based interventions by determining if problematic motives can be directly changed through a coping motive feedbackbased brief intervention utilizing personalized feedback on motives for use and if this change is subsequently related to fewer negative consequences resulting from use. Additionally, given the 


\section{MOTIVES-RELATED FEEDBACK AND DRINKING TO COPE}

strong relationship between coping motives and negative outcomes associated with use, it is possible that a motives-based intervention will be more effective (i.e., will be associated with steeper reductions in use and problems) for individuals who endorse the coping motive at a higher rate.

A second goal of the study is to test a more comprehensive motivational model of drinking to cope with negative affect. The motivational model of alcohol use utilizes a social cognitive approach to analyze an individual's decision to use alcohol (Cox \& Klinger, 1988). This model relies heavily on the role of social cognitive constructs, especially outcome expectancies and current affective states, in the decision to use substances and specific motivations for use. Prior experience with a substance, sociocultural and environment factors, biological predisposition, and personality all contribute to past reinforcement from drinking. Past reinforcement combines with current factors (including immediate situational context, current affective state, and anticipated effects from the substance), to form the expectancy of the effect of the substance. If the expected affective change resulting from consumption is more positive or desirable than the expected affective change from competing behavior, and the individual is in a situation in which they are experiencing negative affect, then alcohol use is likely.

Few studies have examined a comprehensive motivational model of alcohol use. By examining the specific paths of the motivational model, tentative conclusions can be drawn about the progression from characteristics, expectations, and situations of use to the development of motives and subsequent negative consequences associated with use. Cooper and colleagues (1995) have provided support for several relationships in the motivational model - namely that expectancies were associated with coping and enhancement motives, which were associated with various consequences of use. Later research from Cooper and colleagues, found partial concurrent support for link between personality factors, motives, use rates, and consequences of use (Cooper et al., 2000). More recent concurrent research has partially substantiated the links between antecedents of use with motives and outcomes of use (e.g., Buckner, Eggleston, \& 


\section{MOTIVES-RELATED FEEDBACK AND DRINKING TO COPE}

Schmidt, 2006; Ham et al., 2009; Simons et al., 2005), but do not test a more comprehensive model. Partial concurrent support has been found for the relationship between several characteristics and expectations with motives (Read et al., 2003). However, motives did not predict later outcomes, longitudinally. Other longitudinal studies failed to examine all paths in the same model (e.g., Mohr et al., 2013) or have failed to examine the antecedents associated with motives (e.g., Beseler et al., 2008; Cooper et al., 2008; Kuntsche et al., 2008).

Theory suggests that individuals who drink to cope would have a distinct personality style indicative of negative affect and would lack adaptive coping strategies. Indeed, individuals who use to cope with negative affect have a higher rate of negative affect and are more likely to have high levels of anxiety sensitivity and hopelessness (e.g., Conrod et al., 2011; Hecimovic, Barrett, Darredeau, \& Stewart, 2013; Johnson, Mullin, Marshall, Bonn-Miller, \& Zvolensky, 2010; Mitchell, Zvolensky, Marshall, Bonn-Miller, \& Vujanovic, 2007; Woicik, Stewart, Pihl, \& Conrod, 2009). The few studies that have examined the predicted relationship with deficient coping strategies have found mixed support (Blevins, Stephens, Walker, \& Roffman, 2014; Cooper, Russell, \& George, 1988; Corbin, Farmer, \& Nolen-Hoekesma, 2013; Windle \& Windle, 1996). More research is needed to substantiate the theorized relationship between coping motives and coping styles.

According to the motivational model of substance use, expectancies about the effect of a substance help to mold motivation (Cox \& Klinger, 1988). Thus, the coping motive should theoretically be associated with positive expectancies about the effects of substance use, particularly the expectation of reduction of negative affect. However, results from studies that have tested specific expectancies of reduction of negative affect have produced mixed findings (e.g., Cooper et al., 1988; Galen et al., 2001; Kuntsche, Knibbe, Engels, \& Gmel, 2007; Simons, Gaher, Correia, Hansen, \& Christopher, 2005; Stewart, Hall, Wilkie, \& Birch, 2002; Tyne et al., 2011), suggesting the need for research that assesses the incremental impact of expectancies in conjunction with other antecedents of use. 


\section{MOTIVES-RELATED FEEDBACK AND DRINKING TO COPE}

No clear consensus has been found in the literature for the relationship between the coping motive and rates of use. Typically, it is hypothesized that the coping motive should be related to quantity of use but not necessarily frequency of use presumably because individuals who use to cope may be more prone to heavy drinking episodes during times of negative affect rather than a consistently high rate of use (Cooper, 1994). When controlling for other motives, the unique relationship between coping and rates of use has been mixed (Cooper, Agocha, \& Sheldon, 2000; Engels, Wiers, Lemmers, \& Overbeek, 2005; Kuntsche et al., 2007; Read, Wood, Kahler, Maddock, \& Palfai, 2003). Results in longitudinal studies are also unclear (Armeli, Conner, Cullum, \& Tennen, 2010; Cooper et al., 2008; Crutzen, Kuntsche, \& SchellemanOffermans, 2013; Mohr et al., 2013; Salemink \& Wiers, 2014; Schelleman-Offermans, Kuntsche, \& Knibbe, 2011; Windle \& Windle, 2012). Thus, more research is needed to determine the impact of coping motives on rates of use.

Coping has been theorized to be associated with negative use-related consequences. Cooper and others have posited that the coping motive should be related to more use-related problems, above and beyond the effect of rate of use (e.g., Cooper, 1994). This hypothesis stems from the proposition that using to cope is reflective of a lack of adaptive coping strategies thus leads to a more problematic drinking style. Among studies that statistically control for rates of use, the majority of research has found that using to cope has been associated with problems in the alcohol-using adolescent, undergraduate, and adult populations (e.g., Cooper et al., 2000; Cooper, Frone, Russell, \& Mudar, 1995; Simons et al., 2005).

The current study has two broad goals: (1) to evaluate the effectiveness of a feedbackbased brief intervention that provides information and feedback on drinking to cope and (2) to test a cross-sectional structural model of the relationships between theoretical antecedents and consequences of drinking to cope. The specific hypotheses are:

1. A brief intervention incorporating coping motives-related feedback and information will reduce coping motives for alcohol use. 


\section{MOTIVES-RELATED FEEDBACK AND DRINKING TO COPE}

2. Motives-related feedback will be associated with greater reductions in quantity of alcohol use and problems than standard feedback.

3. Coping motives measured at baseline will moderate the effect of the intervention such that those with higher levels of the coping motive will show the largest reductions in quantity of alcohol use and related problems in the coping motive intervention condition.

4. Reductions in drinking to cope will mediate the effect of the intervention on quantity of alcohol use and consequences of use.

5. Individuals who drink alcohol to cope will have higher rates of negative affect; be more likely to endorse avoidant or other maladaptive coping styles: and hold more expectancies of reduction of negative affect.

6. Coping-motivated drinkers will report higher quantity of alcohol use and more userelated problems above and beyond use.

\section{Methods}

\section{Participants}

Participants were undergraduates from Virginia Tech who were enrolled in psychology classes. Eligibility criteria included: age of at least 18, average use of alcohol at least two days per week, and willingness to complete a follow-up assessment approximately two months later. A total of 170 participants were eligible for and participated in the initial in-lab intervention portion of the study. Analyses of demographic variables indicated that participants were primarily female $(73.5 \%)$ and Caucasian $(79.4 \%)$, which approximates the psychology undergraduate population at Virginia Tech. The mean age of participants was 19.71 years ( standard deviation $=1.42$ years) .

\section{Design}

The current study examined the impact of personalized feedback with an emphasis on how drinking to cope may lead to higher rates of use and more negative consequences associated with use. The comparison condition received personalized feedback without a motives emphasis. 


\section{MOTIVES-RELATED FEEDBACK AND DRINKING TO COPE}

Participants were screened for eligibility and, after informed consent procedures were completed, were administered a baseline assessment battery in a laboratory setting. Following completion of the baseline measures, participants were randomized to condition. Participants in the Motives Feedback Condition (MFC; $\mathrm{n}=87$ ) were given personalized feedback surrounding their use and consequences associated with use, as well as coping motive-based feedback, coping motive-based education, and alternate coping strategies. Individuals in the Standard Feedback Condition (SFC; $\mathrm{n}=83$ ) were only given the personalized feedback surrounding their use and consequences. Participants were re-assessed two months after baseline to determine changes in motives, drinking, and consequences. The effect size was expected to be moderate (estimated $d=.50$ ), based on previous studies of brief interventions that have found small to medium effects of treatment on outcome measures (Conrod et al., 2011; LaBrie et al., 2008; Moyer, Finney, Swearingen, \& Vergun, 2002; Vasilaki, Hosier, \& Cox, 2006). Based on our sample size of 159 who completed assessments at both timepoints, the power to detect this effect is .88 when utilizing a mixed model GLM, under the assumption that alpha $=.05$ (G*Power 3; Faul, Erdfelder, Lang, \& Buchner, 2007).

\section{Procedures}

Participants were recruited through the university's Psychology department SONAsystem. Procedures and measures were approved by the Virginia Tech Institutional Review Board. Students taking psychology courses who were interested in gaining extra credit had the opportunity to read a description of the study, which was advertised as the Alcohol Feedback Project (see Appendix N), and sign up for participation. The Alcohol Feedback Project was advertised as a study that evaluated the usefulness of different types of feedback surrounding alcohol use, and described the eligibility criteria, time commitment, and compensation.

Baseline measures were obtained and the intervention was conducted in person in a research office. Participants met with research staff to first determine eligibility. They gave initial consent for the screening questions and were asked about their age and days per month of 


\section{MOTIVES-RELATED FEEDBACK AND DRINKING TO COPE}

alcohol use in order to determine eligibility (see Appendix $\mathrm{O}$ for consent for screening and screening questions). If participants were eligible for the study (meaning that they are at least 18 years of age, consume alcohol on at least two days per week, and are willing to complete a follow-up survey), then they were randomized into either the MFC or typical SFC condition. Participants were informed of study procedures and incentives, and provided their desired method of contact, either text or email, for follow-up measures. After eligible participants consented to participation in the study (see Appendix P), they completed a computerized assessment which assessed demographics, alcohol and other drug use, motives for use, situations of use, drinking companions and locations, consequences, descriptive and injunctive norms, importance and confidence of change, stage of change, expectancies of use, coping strategies, and risky personality profiles (see Appendices for details). Research assistants were available to answer questions, as needed.

After completion of the assessment, participants received a personalized feedback report that included motives information (MFC; see Appendix R) or a personalized feedback report without motives information (SFC; see Appendix Q). The personalized feedback report of both conditions included normative information and consequences associated with use.

The MFC condition differed from the SFC condition because the personalized feedback report also includes motives-specific feedback, consequences associated with the coping motive, and a list of alternate coping strategies. This combination of coping motive-feedback, education, and coping strategies is hypothesized to be useful to participants by drawing attention to their own problematic motives for use and helping them to develop adaptive coping strategies that are independent of alcohol use. Participants were given a brief introduction to the document and then were presented with their personalized feedback. Study staff guided participants through the document. Throughout the course of feedback, study staff elicited responses from participants regarding their understanding of and interpretation of information. After receiving and reviewing 


\section{MOTIVES-RELATED FEEDBACK AND DRINKING TO COPE}

the personalized feedback report, participants in each condition completed a brief manipulation check to ensure that they received the intended information.

Two months after completion of baseline measures, participants in both conditions were contacted via email and/or text to complete a follow-up assessment. The follow-up assessment included all measures from the baseline assessment, and was completed online. Thus, the assessment could be completed from a location of the participant's choosing. Participants who completed the follow-up measure were entered to win one of twenty-three $\$ 25$ gift cards.

\section{Measures}

\section{Demographics.}

Participants answered a variety of demographic questions during their initial baseline session (see Appendix A). They provided information on their age, gender, and racial or ethnic background.

\section{Motives for Substance Use.}

A more recent adaptation of the DMQ, the Modified DMQ-R, was utilized at baseline and follow-up. The Modified DMQ-R expands the coping motive to reflect two distinct forms of coping: coping with anxiety and coping with depression (Grant, Stewart, O'Connor, Blackwell, \& Conrod, 2007). The Modified DMQ-R is a 28 item questionnaire assessing five motives for substance use: coping with anxiety, coping with depression, enhancement, social, and conformity (see Appendix B). Participants were asked to rate how frequently they use alcohol for the reason specified on a scale of 1 (almost never/never) to 5 (almost always/always). For the purposes of the following analyses, the coping with anxiety and coping with depression subscales of the Modified DMQ-R were used to evaluate the effectiveness of the motives-related feedback and in the evaluation of the motivational model of use. In order to determine whether the coping scales should be combined for analyses, a principle components analyses was performed. Results suggested a two-factor solution. Cronbach's alphas for the Modified DMQ-R subscales were as 


\section{MOTIVES-RELATED FEEDBACK AND DRINKING TO COPE}

follows: coping with anxiety .71 at baseline and .76 at follow-up; coping with depression was from .92 at baseline and .95 at follow-up.

\section{Risky Personality Profiles.}

Personality factors were measured at baseline and follow-up utilizing the Substance Use Risk Profile Scale (SURPS), a brief, 23-item personality measure designed to specifically assess for personality subtypes that are indicative of vulnerability to substance use (Woicik et al., 2009). Participants rated the extent to which they agreed to each item on a scale of 1 (strongly disagree) to 4 (strongly agree). Four personality subtypes are measured: anxiety sensitivity, hopelessness, impulsivity, and sensation-seeking (see Appendix C). For the purposes of these analyses, the anxiety sensitivity and hopelessness subscales were utilized as manifest variables to operationalize the latent variable of degree of negative affect in tests of the motivational model. The anxiety sensitivity scale included five items (e.g., "I get scared when I am too nervous"), while the hopelessness scale included six items that were reversed scored (e.g., "I am content"). Cronbach's alphas indicated good reliability, with alpha coefficients for the hopelessness scale of .68 at baseline and follow-up and anxiety sensitivity alpha coefficients of .69 and .71 .

\section{Coping}

The Brief COPE Inventory is a 28 -item measure that assesses a broad range of coping strategies for difficult life situations (see Appendix G). For the purpose of this study, the following subscales were utilized to represent maladaptive coping: denial, behavioral disengagement, and self-blame. The measure, which was administered at baseline and follow-up, was utilized to test the more comprehensive motivational model of use. The COPE asks participants how often they respond in a certain way to stressful or difficult situations on a scale of 1-4: 1, "I usually don't do this at all"; 2, "I usually do this a little bit"; 3, "I usually do this a medium amount"; and 4, "I usually do this a lot" (Carver, 1997). Cronbach's alphas for the individual subscales were as follows: denial .58 and .61 , behavioral disengagement .67 and .67 , and self-blame .78 and.79. 


\section{MOTIVES-RELATED FEEDBACK AND DRINKING TO COPE}

\section{Expectancies of Use.}

The Alcohol Expectancy Questionnaire-3 (AEQ-3; George et al., 1995) is a 40-item questionnaire adapted from the 120-item Alcohol Expectancy Questionnaire (Brown, Christiansen, \& Goldman, 1987) and 40-item Alcohol Effects Questionnaire, Second Version (AEQ-2; D. J. Rohsenow, 1983). It was administered at baseline and follow-up sessions (see Appendix H). The AEQ-3 is designed to assess for six positive (global positive, social and physical pleasure, social expressiveness, sexual enhancement) and two negative subscales of alcohol use expectancies (power and aggression, and cognitive and physical impairment). For the purpose of this study, the global positive and tension reduction and relaxation subscales were included to assess constructs related to the motivational model of use. For the purpose of the structural equation model, the manifest subscales of global positive and tension reduction and relaxation were used to represent the latent variable of positive expectancies. Items are answered using a six-point Likert-type scale (from agree strongly to disagree strongly). Alpha reliabilities ranged were .69 at baseline and .80 at follow-up for the global positive subscale and .61 at baseline and .76 at follow-up for the tension reduction and relaxation subscale, indicating good reliability.

\section{Substance Use}

To assess use of alcohol, individuals were asked about their quantity and frequency of alcohol use during the past 30 days with the Daily Drinking Questionnaire-Revised (DDQ-R; Kruse, Fromme, \& Corbin, 2005). The DDQ-R assesses for quantity of use, days of use, and hours spent using in a typical week and during a heavy week (see Appendix J). For the purposes of this study, the number of drinks per week on a typical week was utilized as the measure of alcohol use. The assessment was given at baseline and follow-up, and was utilized as a measure of outcome in the intervention as well as for the motivational model of use.

\section{Problems}




\section{MOTIVES-RELATED FEEDBACK AND DRINKING TO COPE}

The Rutgers Alcohol Problem Index (RAPI) is a 23-item measure designed to assess a variety of consequences associated with use (White \& LaBouvie, 1989; see Appendix K). The RAPI has good to excellent psychometric properties. Although originally developed in an adolescent population, it has been extensively used in the college population. The RAPI was administered at baseline and follow-up sessions with an assessment window of one month, and was utilized as both a measure of outcomes in the intervention and in the motivational model of use. Cronbach's alpha reliability coefficients were .77 at baseline and .85 at follow-up, indicating good reliability.

\section{Manipulation Check}

Participants in both conditions were asked five questions regarding the information they received in their personalized feedback reports (see Appendix M). Two of the questions targeted information on the coping motive and negative outcome associated with the coping motive that was specific to the MFC condition (Appendix M, questions 1 and 3) while the other three questions were about information present in the personalized feedback reports of both conditions, including information on normative rates of alcohol use and consequences of alcohol use (questions 2, 4, and 5).

\section{Results}

\section{Preliminary Analyses}

Several preliminary analyses were conducted prior to testing hypotheses. Examination of the distributions of measures indicated adequate variation at both time points and no evidence of floor or ceiling effects. Comparisons of variables of interest by condition revealed no significant differences, suggesting that randomization to condition was successful. Out of the 170 participants who completed baseline assessment, 159 participants completed both the initial in-lab portion and the follow-up survey (93.5\%). Only one participant out of 159 had missing data because they did not complete a portion of the follow-up survey. Two-way attrition by condition ANOVAs performed on baseline characteristics of the sample showed a main effect of use on 


\section{MOTIVES-RELATED FEEDBACK AND DRINKING TO COPE}

attrition status at follow-up ( $p=.03)$, but no other main effects or significant interactions between baseline characteristics and condition. Detecting Careless Responding

Given that approximately $10-12 \%$ of undergraduates who participate in online surveys may respond carelessly (Meade \& Craig, 2012), five items were inserted into the survey battery to test for careless reporting styles. These items directed participants to select a particular answer. If participants failed to follow the instructions for more than 1 of these items they were to be deemed to be responding carelessly and their data would not have been utilized for analyses. However, only 5 participants answered an item incorrectly and no participants answered more than 1 item incorrectly.

\section{Manipulation Check}

The first analysis evaluated responses to the three questions that participants in both conditions should have been able to answer correctly. Overall, the vast majority of participants answered questions correctly regarding the lack of relationship between number of drinks consumed and diagnostic labels (91.6\% in SFC condition, 87,4\% in MFC condition; $p=.38$ ), rate of use in their school community (98.8\% in SFC condition, $95.4 \%$ in MFC condition; $p=.19$ ), and alcohol use among college students nationwide (89.2\% in SFC condition, $86.2 \%$ in MFC condition; $p=.56)$.

Two questions were taken from information only given to the MFC condition. Answers to those two questions revealed $94.3 \%$ of individuals in the MFC condition were able to correctly identify the coping motive as being associated with the most negative consequences (as opposed to $15.7 \%$ in the SFC condition; $p<.01$ ) and $97.7 \%$ could identify that specific negative consequences of use (as opposed to $30.1 \%$ in the SFC condition; $p<.01$ ). These findings indicate that participants received the intended information and that the coping motives information was received uniquely in the MFC condition.

\section{Goal 1: Coping-Motives Based Intervention}




\section{MOTIVES-RELATED FEEDBACK AND DRINKING TO COPE}

The first goal of the project was to evaluate the effectiveness of the coping motive-based intervention on rates of use and negative consequences associated with use. Specifically, hypotheses 1-4 were evaluated: (1) a brief coping motives-related intervention will reduce coping motives for alcohol use; (2) motives-related feedback will be associated with a reduction in quantity of use and number of use-related problems; (3) coping motives at baseline will moderate intervention effects such that higher coping motives will be associated with the largest reductions in quantity of use and use-related problems among those in the MFC condition; and (4) reductions in the coping motive will mediate the relationship between the intervention and quantity of use and consequences.

\section{Descriptive Statistics}

Table 1 contains means and standard deviations of variables utilized in Goal 1 analyses at baseline and follow-up. Notably, participants averaged 13.5 drinks per week at baseline $(\mathrm{SD}=$ 8.8), suggesting that participants with a variety of drinking habits were recruited. Participants endorsed 6.7 problems, on average, on the RAPI ( $\mathrm{SD}=5.22)$. Coping with anxiety was endorsed somewhat more frequently than coping with depression (mean of 2.12 versus 1.51 out of 5).

\section{Effects of the Intervention}

Repeated measures General Linear Model (GLM) analyses with condition as betweensubjects factor were utilized to test the hypothesized effects of the intervention. Separate equations were used to test the effects of the intervention on the coping motives, quantity of alcohol use, and alcohol-related problems by condition.

Changes in Coping Motives. The first hypothesis was that the coping motives-related feedback would reduce rates of the coping motive. A time by condition effect was predicted and post hoc comparisons of means at the follow-up were expected to show lower rates of the coping motives in the MFC condition. GLM analyses revealed significant effects of time for the coping with anxiety $(\mathrm{F}(1,157)=8.56 ; p<.01)$ and coping with depression $(\mathrm{F}(1,157)=6.35 ; p=.01)$ motives

(Table 1). Further, a significant time by condition effect was found for the coping with 


\section{MOTIVES-RELATED FEEDBACK AND DRINKING TO COPE}

depression motive $(\mathrm{F}(1,157)=12.49 ; p<.01)$. The corresponding interaction for the coping with anxiety motive did not reach conventional levels of statistical significance $(\mathrm{F}(1,157)=3.41$; $p=.07)$. Between groups t-tests at follow-up indicated that those in the MFC condition reduced rates of the coping motives more than those in the SFC condition (see Table 1).

Changes in Alcohol Use and Related Problems. Repeated measure GLM analyses were again performed to test the second hypothesis, that motives-related feedback would be associated with significant reductions in quantity of use and alcohol-related problems (see Table 1 and Figures 1 and 2). Again, a time by condition F-statistic was predicted such that comparisons of means at the follow-up were expected to show less alcohol use and fewer negative consequences in the MFC condition. Results indicated a significant effect of time on quantity of alcohol use $(\mathrm{F}(1,157)=27.32 ; p<.01)$ and alcohol-related problems $(\mathrm{F}(1,156)=17.87 ; p<.01)$. However, there were no time by condition interactions for either quantity of use $(\mathrm{F}(1,157)=1.81$; $p=.18)$ or problems $(\mathrm{F}(1,156)=2.26 ; p=.14)$.

\section{Differences by Baseline Level of Coping Motives.}

To test hypothesis three, that coping motives at baseline would moderate the intervention effect, multiple regression was utilized. Separate regression equations regressed quantity of alcohol use and alcohol problems on coping motives and moderator predictors. It was posited that those with higher levels of coping motive at baseline would benefit the most from the coping intervention and show greater reductions in quantity of use per week and use-related problems in the MFC condition than expected based on main effects. In the first step of the regression equation, the centered coping variable and the condition variable (dummy coded) were entered along with the baseline levels of the criterion (either use or problems) in order to predict change. In the second step, an interaction term was entered to test the hypothesis that level of coping motives at baseline moderates the effect of the intervention. These interaction terms were created as a product of the centered, coping and treatment variables and were expected to be significant predictors in support of moderation effects. Thus, four regression equations were tested based on 


\section{MOTIVES-RELATED FEEDBACK AND DRINKING TO COPE}

the two coping motives (coping with anxiety and coping with depression) and two outcomes (quantity of alcohol use and alcohol use-related problems). As can be seen in Table 2 only one interaction approached conventional levels of statistical significance for the effect of coping with depression and condition $(p=.08)$ predicting quantity of use.

\section{Change in Coping as Mediators of Intervention Effects.}

The fourth hypothesis tested whether reductions in using to cope would mediate the effect of the intervention on alcohol use and consequences associated with use. Due to the criticisms of the Baron and Kenney (1986) model and causal models in general surrounding the lack of power to find effects, a method that specifically tests for indirect effects was utilized to test potential mediators (Hayes, 2009). The mediational hypothesis was evaluated using Hayes and Preacher's Process SPSS macro (Preacher \& Hayes, 2008). This macro allows for bootstrapping of conditional indirect effects and has higher power to detect effects. It was expected that the change in coping motives would partially mediate the relationship between baseline measures and measures of use and negative consequences such that individuals with greater reductions in coping motives would experience greater reductions in quantity of use and problems. See Figure 4 for an illustration of the predictions.

First, change scores were computed for each of the coping motives by subtracting the baseline values from the follow-up values. Four separate bootstrapping analyses were performed: (a) change in coping with anxiety mediating the effect of the intervention on quantity of use, (b) change in coping with anxiety mediating the effect of the intervention on problems, (c) change in coping with depression mediating the effect of the intervention on quantity of use, and (d) change in coping with depression mediating the effect of the intervention on problems. All analyses controlled for corresponding level of use or problems at baseline in order to examine change in the alcohol outcomes.

When testing change in coping with anxiety as a mediator between the intervention and follow-up quantity of alcohol use per week, the intervention did not significantly predict change 


\section{MOTIVES-RELATED FEEDBACK AND DRINKING TO COPE}

in coping with anxiety $(b=-.19 ; p=.06)$, and change in coping with anxiety did not significantly predict follow-up alcohol use per week $(b=1.17 ; p=.12)$. The bootstrapped indirect effect was not significant $(b=-.22 ; \mathrm{CI}=-.82-.07)$. For the equation testing change in anxiety as a mediator between the intervention and follow-up rates of alcohol problems, condition did not significantly predict change in coping with anxiety $(b=-.18 ; p=.07)$, but change in coping with anxiety predicted follow-up problems $(b=1.14 ; p=.03)$. However, the bootstrapped indirect effect was not significant $(b=-.21 ; \mathrm{CI}=-.99-.01)$. In testing coping with depression as a mediator, the intervention significantly predicted change in coping with depression $(b=-.30 ; p<.01)$, and change in coping with depression significantly predicted quantity of alcohol use at the follow-up $(b=1.91 ; p=.03)$. The bootstrapped indirect effect of coping with depression on use at followup was significant $(b=-.57 ; \mathrm{CI}=-1.50$ to -.08$)$. Lastly, the intervention predicted change in coping with depression $(b=-.29 ; p<.01)$ and change in coping with depression significantly predicted a problems at follow-up $(b=1.98 ; p<.01)$. The bootstrapped indirect effect of the mediator on the outcome was significant $(b=-.57 ; \mathrm{CI}=-1.60$ to -.02$)$.

\section{Goal 2: Motivational Model of Alcohol Use}

The second goal of the study was to test a comprehensive version of the motivational model of substance use in a college population utilizing cross-sectional data from baseline. Specifically, hypotheses 5 and 6 were evaluated: (5) individuals who endorse the coping motive will have higher rates of negative affect, avoidant/maladaptive coping styles, and expectancies regarding reduction of negative affect; and (6) coping-motivated users will report higher quantity of alcohol use per week and more alcohol-related problems above and beyond quantity of use. Additionally, indirect effects represented in the motivational model were explored.

Figure 3 depicts the hypothesized model. The structural model was tested using Mplus version 6 (Muthén \& Muthén, 1998-2011). In order to determine model fit, several indices were used: chi-square values, degrees of freedom, p-values, the Comparative Fit Index (CFI) and the Root Mean Square Error of Approximation (RMSEA). Cut-offs of .10 were used for the RMSEA 


\section{MOTIVES-RELATED FEEDBACK AND DRINKING TO COPE}

and .90 to .95 for CFI, based on suggestions by Hu and Bentler $(1998,1999)$ and Kline $(2005)$. Lastly, the alcohol use variable was tested as a mediator in a series of two-path models (see Taylor, MacKinnon, \& Tein, 2007) utilizing the Hayes SPSS macro. Evaluation of the motivational model used only baseline data collapsed across condition. Table 3 contains means, standard deviations, and correlations among variables used in goal 2 of the study.

\section{Full Structural Equation Model}

Results are presented in Figure 5. These analyses evaluated the relationship between maladaptive coping strategies, positive expectancies, negative affect, coping motives, rates of alcohol use, and problems associated with use. This model had a $\chi 2=71.78, \mathrm{df}=56, p<.01$; CFI $=.93, \mathrm{RMSEA}=.076, p<.05$, indicating good model fit. Modification indices were examined for any modifications that were simultaneously theoretically-justified and which improved model fit. As such, Anxiety Sensitivity and Use were allowed to correlate.

The first step of the SEM model was to evaluate the factor loadings of subscales used to form latent variables of coping with negative affect, maladaptive coping, positive expectancies, and negative affect. As represented in Figure 5, the coping with negative affect latent variable was represented by the coping with depression and coping with anxiety motives. Coping with depression significantly loaded onto the coping with negative affect latent variable $(b=.86, \mathrm{SE}=$ $.03, p<.01)$, as did the coping with anxiety variable $(b=.82, \mathrm{SE}=.03, p<.01)$. Maladaptive coping style was computed through the manifest variables of denial coping $(b=.66, \mathrm{SE}=.07, p$ $<.01)$, behavioral disengagement coping $(b=.71, \mathrm{SE}=.06, p<.01)$, and self-blame coping styles $(b=.56, \mathrm{SE}=.07, p<.01)$. Positive expectancies was represented through the manifest variables of global positive expectancies $(b=.85, \mathrm{SE}=.05, p<.01)$, and tension reduction expectancies $(b$ $=.68, \mathrm{SE}=.05, p<.01)$. Negative affect was represented through manifest variables of the anxiety sensitive risk profile $(b=.43, \mathrm{SE}=.09, p<.01)$ and the hopelessness risk profile $(b=.58$, $\mathrm{SE}=.09, p<.01)$. Overall, these results indicate that theorized manifest variables are significantly associated with latent constructs. 


\section{MOTIVES-RELATED FEEDBACK AND DRINKING TO COPE}

Hypothesis five evaluated the relationship of maladaptive coping styles, positive expectancies surrounding use, and negative affect with the motive of coping with negative affect. As presented in Figure 5, maladaptive coping styles were not associated with coping with negative affect $(b=.18, \mathrm{SE}=.28, p=.52)$, nor was negative affectivity $(b=.26, \mathrm{SE}=.35, p$ =.75). However, positive expectancies surrounding alcohol use were significantly associated with coping with negative affect $(b=.63, \mathrm{SE}=.12, p<.01)$. These findings indicate that individuals with maladaptive coping styles and risky personality profiles indicative of negative affect did not significantly endorse using alcohol for the motive of coping with negative affect, but that those with positive expectancies surrounding alcohol use were more likely to endorse coping with negative affect. Thus, hypothesis 5 was only partially supported.

Hypothesis six evaluated the relationships between coping with negative affect, quantity of alcohol use, and alcohol-related problems. It was expected that coping with negative affect would be associated with problems and use, and quantity of use would be associated with problems. Coping with negative affect was significantly related to problems associated with use $(b=.37, \mathrm{SE}=.07, p<.01)$, but not overall quantity of use $(b=.07, \mathrm{SE}=.08, p=.43)$. However, overall quantity of use were significantly associated with problems $(b=.25, \mathrm{SE}=.07, p<.01)$. These results indicate that individuals who used alcohol for the motive of coping with negative affect and individuals who reported higher quantity of use per week were more likely to have problems associated with use. Overall, hypothesis six was partially supported.

\section{Indirect Effects}

Several indirect effects were tested in a series of two-path and three-path mediation models (see Taylor, MacKinnon, \& Tein, 2007) utilizing the Hayes SPSS macro. The first twopath test was tested to determine if quantity of alcohol consumed per week mediated the relationship between drinking to cope with negative affect and problems associated with use. Results indicated a non-significant bootstrapped indirect effect $(b=.05 ; \mathrm{CI}=-.07-.33)$. Lastly, 


\section{MOTIVES-RELATED FEEDBACK AND DRINKING TO COPE}

the two-path test from expectancies to problems through drinking to cope was tested. Results indicated a non-significant bootstrapped indirect effect $(b=.36 ; \mathrm{CI}=-.12-.86)$.

\section{Discussion}

The present study investigated the relationship of drinking to cope with alcohol use and related problems in two ways. First, the impact of adding feedback on coping motives to a typical feedback-based intervention on weekly quantity of alcohol use and alcohol-related problems was evaluated. Results indicated that feedback on using alcohol to cope reduced reports of using alcohol to cope with depressed affect at follow-up, but not with anxious affect. Significant reductions in quantity of alcohol use and alcohol-related problem were also evident at follow-up, but did not differ significantly as a function of the coping motive feedback. Change in drinking to cope with depression was a significant mediator of the intervention on both quantity of use and alcohol problems. Baseline levels of coping did not moderate the effect of the intervention. Second, the study evaluated the relationship of drinking to cope with both antecedent constructs and predicted consequences in order to evaluate a more complete motivational model. As predicted, expectancy of positive effects from alcohol use was significantly associated with the coping motive. However, a more general maladaptive coping style and trait negative affectivity were not. Drinking to cope was significantly associated with alcohol-related problems, but not with quantity of use even though rates of alcohol use predicted problems as hypothesized. Overall, the findings support the importance of the coping motive in predicting negative consequences of use and suggest avenues for future research.

The brief intervention targeting the coping motive significantly affected the tendency to drink alcohol to cope with negative affect. Significant reductions in drinking to cope with depressed affect were evident following the brief intervention and were greater among those who received feedback on the risk of using alcohol to cope. However, the effect did not quite reach conventional levels of statistical significance for drinking to cope with anxiety. Average number of drinks per week and use-related problems significantly decreased at follow-up, but did not 


\section{MOTIVES-RELATED FEEDBACK AND DRINKING TO COPE}

differ across conditions. Nevertheless, there was evidence that changes in drinking to cope with depression mediated the impact of the intervention on quantity of alcohol use and related problems.

The different findings for drinking to cope with depression versus anxiety were not predicted. The effect size (Cohen's d) for drinking to cope with depression was .49 while the effect size for coping with anxiety was .28 . These effect sizes are in the range of those reported for other brief interventions when compared to no treatment (Moyer et al., 2002; Vasilaki et al., 2006). Studies that have analyzed the impact of incremental features of brief interventions (e.g., normative feedback; Neighbors, Lewis, Bergstrom, \& Larimer, 2006) typically find small effects. Similarly, the mediational analyses, although not quite reaching conventional levels of statistical significance, suggested that changes in coping with anxiety may be related to changes in drinking and drinking problems. Therefore, even the relatively small effect for coping with anxiety may represent a meaningful addition to brief interventions, especially considering the low cost of adding this additional feedback to typical brief interventions. In general, the brevity of the intervention and ease of implementation argue for further study.

The relatively smaller effect on coping with anxiety may be related to differences in the nature and prevalence of anxious affect. Coping with anxiety was endorsed at a higher rate than coping with depression in this study, which is consistent with previous studies utilizing the Modified DMQ-R (Grant et al., 2007; Willem, Bijttebier, Claes, \& Uytterhaegen, 2012). Differences in effect sizes suggest that coping with anxiety - or anxiety itself - may be a more difficult factor to affect in interventions for alcohol use. A review of the anxiety and motives literature has established the links between anxiety, anxiety sensitivity, motives and use (Demartini \& Carey, 2011). Indeed, previous literature established the link between anxiety and alcohol use and has shown that anxiety often persists after treatment and can predict less impactful treatment outcomes (Kushner et al., 2005). Additionally, evidence from an ecological momentary assessment study of direct antecedents and consequences of use found that anxiety 


\section{MOTIVES-RELATED FEEDBACK AND DRINKING TO COPE}

was a predictor of marijuana use, and that this anxiety persisted throughout the time that the individual used marijuana (Buckner, Crosby, Silgado, Wonderlich, \& Schmidt, 2012). Thus, anxiety may be a stable, chronic factor that predicts substance use and use-related consequences.

Contrary to hypotheses, initial levels of drinking to cope did not moderate the effect of the intervention on outcomes by conventional statistical standards. Perhaps the lack of significant moderation findings can be explained by features of the sample. The study recruited a normative college population with a variety of use patterns, ranging from use on two days per week (the minimum for eligibility) to seven days per week, two drinks per week to sixty-one, and a score of zero to twenty-seven on the problems scale. Thus, the effort to recruit participants with a variety of drinking patterns may have limited our findings regarding the importance of the coping motive. The moderation effect of baseline level of coping motive was hypothesized to be significant among those who endorse high levels of the coping motive, as opposed to low levels. Given our normative sample, it is probable that we did not recruit a large proportion of individuals on the higher end of coping motives. Indeed, endorsement of the coping motives in our sample was consistent with other normative, undergraduate samples (Grant et al., 2007) and significantly lower than clinical samples (Mezquita et al., 2011). Perhaps the coping motive would be a significant moderator of outcomes in a more heavy-using, clinical sample.

Recruitment of treatment-seeking individuals may have yielded significant moderation effects or steeper reductions in negative outcomes (e.g., DiClemente, Bellino, \& Neavins, 1999).

Another possible limitation was the evidence of differential attrition at follow-up. Future research should examine ways to make interventions more appealing to heavier users. Despite limitations of the sample and the relatively brief follow-up period, the results are promising. Further study of interventions specifically targeting drinking to cope with negative affect appear warranted. Designs including longer follow-ups, more problematic samples, and perhaps additional types of motive feedback are needed. 


\section{MOTIVES-RELATED FEEDBACK AND DRINKING TO COPE}

A secondary goal was to test a more comprehensive model of drinking to cope by examining theoretically related antecedents of the coping motive in addition to consequences of drinking to cope using cross-sectional data collected at baseline. Positive expectancies for the effects of alcohol were significantly associated with coping motives as predicted. This finding is consistent with the seminal theoretical research on the motivational model of use (Cox \& Klinger, 1988). However, positive expectancies were not associated with outcomes through drinking to cope. Unexpectedly, other proposed antecedents of use - maladaptive coping and negative affectivity - did not emerge as constructs that systematically predicted drinking to cope despite significant univariate relationships between the manifest variables. The coping motive theoretically arises due to an individual's lack of other adaptive coping strategies to cope with negative affect. The lack of significance in paths from maladaptive coping and negative affectivity constructs to the coping motive may be due to lower power or due to the inclusion of other salient predictors of the coping motive (i.e., positive expectancies surrounding effects of alcohol use). It is also possible that separate models relating specific antecedents of anxiety and depression may better capture relationships than a focus on a negative affect more globally. Additionally, perhaps by utilizing a risky personality profile scale, we were not adequately measuring anxiety sensitivity or hopelessness. Thus, future research should utilize a more empirically-supported measure of trait negative affectivity.

Results from direct and indirect paths from coping motive to outcomes indicated a significant association with alcohol-related problems, but not quantity of alcohol use. Previous literature has consistently found a link between the coping motive and problematic outcomes (e.g., Blevins \& Stephens, under review; Cooper, 1994; Simons et al., 2005). However, the evidence is mixed for relationships between the coping motive and rates of use, with studies utilizing a quantity of use measure generally reporting more robust relationships (e.g., Blevins \& Stephens, under review; Cooper et al., 2000; Engels et al., 2005; Kuntsche et al., 2007; Read et al., 2003). Despite utilizing a quantity measure over frequency, this study failed to find 


\section{MOTIVES-RELATED FEEDBACK AND DRINKING TO COPE}

significant associations in the motivational model. It is possible that individuals who drink to cope may not consume alcohol at a high quantity on a regular basis, but may be more prone to binging episodes. Future research may benefit from utilizing a measure of binge episodes in addition to measures of quantity of alcohol use. Alternately, perhaps the theorized link between using to cope and rates of use may be inconsistent due to some moderating factor not included in the current study.

A major limitation of the motivational model tested in this study is that the crosssectional nature of these data preclude drawing causal inferences. Future studies are needed that focus on the development of the coping motive and subsequent outcomes in a longitudinal design. Additional research utilizing larger samples that utilize other indicators of use may yield more robust effects. Moreover, future studies should consider modeling coping with anxiety and coping with depression as separate paths rather than one construct. Given that our sample was primarily female and Caucasian, it is uncertain the extent to which findings could generalize beyond this population. Additionally, participants were less than 20 years of age, on average, and were not of legal age to consume alcohol. Future research should examine these research questions in a more diverse population. Given that all measures were self-report and that many participants were below the legal drinking age, it would be useful to add an observer measure to future studies in order to evaluate the accuracy of responses.

Literature on substance use motives is proliferating at a high rate, and these results provide a promising new direction for motives research and substance use treatment. The current study has demonstrated the importance of motives - particularly the coping motive - and the ability to affect motives via brief interventions. Motives-focused interventions may be a costeffective, feasible option for a variety of substance using populations. 


\section{References}

Armeli, S., Conner, T. S., Cullum, J., \& Tennen, H. (2010). A longitudinal analysis of drinking motives moderating the negative affect-drinking association among college students. Psychology of Addictive Behaviors, 24(1), 38-47.

Banes, K. E., Stephens, R. S., Blevins, C. E., Walker, D. D., \& Roffman, R. A. (2014). Changing motives for use: Outcomes from a cognitive-behavioral intervention for marijuanadependent adults. Drug and Alcohol Dependence, 139, 41-46.

Baron, R. M., \& Kenny, D. a. (1986). The moderator-mediator variable distinction in social psychological research: conceptual, strategic, and statistical considerations. Journal of Personality and Social Psychology, 51(6), 1173-82.

Beseler, C. L., Aharonovich, E., Keyes, K. M., \& Hasin, D. S. (2008). Adult transition from atrisk drinking to alcohol dependence: the relationship of family history and drinking motives. Alcoholism, Clinical and Experimental Research, 32(4), 607-16.

Blevins, C. E., \& Stephens, R. S. (n.d.). A Critical Evaluation of the State of Motives for Substance Use Literature.

Blevins, C. E., Stephens, R. S., Walker, D. D., \& Roffman, R. A. (2014). Situational determinants of use and treatment outcomes in marijuana dependent adults. Addictive Behaviors, 39, 546552.

Brown, S. A., Christiansen, B. A., \& Goldman, M. S. (1987). The Alcohol Expectancy Questionnaire: An instrument for the assessment of adolescent and adult alcohol expectancies. Journal of Studies on Alcohol and Drugs, 48(5), 483-491.

Buckner, J. D., Crosby, R. D., Silgado, J., Wonderlich, S. a, \& Schmidt, N. B. (2012). Immediate antecedents of marijuana use: an analysis from ecological momentary assessment. Journal of Behavior Therapy and Experimental Psychiatry, 43(1), 647-55.

Buckner, J. D., Eggleston, A. M., \& Schmidt, N. B. (2006). Social anxiety and problematic alcohol consumption: The mediating role of drinking motives and situations. Behavior Therapy, 37(4), 381-391.

Carver, C. S. (1997). You want to Measure Coping But Your Protocol's Too Long: Consider the Brief COPE. International Journal of Behavioral Medicine, 4(1), 92.

Conrod, P. J., Castellanos-Ryan, N., \& Mackie, C. (2011). Long-term effects of a personalitytargeted intervention to reduce alcohol use in adolescents. Journal of Consulting and Clinical Psychology, 79(3), 296-306.

Conrod, P. J., Stewart, S. H., Pihl, R. O., Côté, S., Fontaine, V., \& Dongier, M. (2000). Efficacy of brief coping skills interventions that match different personality profiles of female substance abusers. Psychology of Addictive Behaviors, 14(3), 231-242. 


\section{MOTIVES-RELATED FEEDBACK AND DRINKING TO COPE}

Cooper, M. L. (1994). Motivations for alcohol use among adolescents: Development and validation of a four-factor model. Psychological Assessment, 6(2), 117-128.

Cooper, M. L., Agocha, V. B., \& Sheldon, M. S. (2000). A motivational perspective on risky behaviors: The role of personality and affect regulatory processes. Journal of Personality, 68(6), 1059-1088.

Cooper, M. L., Frone, M. R., Russell, M., \& Mudar, P. (1995). Drinking to regulate positive and negative emotions: A motivational model of alcohol use. Journal of Personality and Social Psychology, 69(5), 990-1005.

Cooper, M. L., Krull, J. L., Agocha, V. B., Flanagan, M. E., Orcutt, H. K., Grabe, S., ... Jackson, M. (2008). Motivational pathways to alcohol use and abuse among Black and White adolescents. Journal of Abnormal Psychology, 117(3), 485-501.

Cooper, M. L., Russell, M., \& George, W. H. (1988). Coping, expectancies, and alcohol abuse: A test of social learning formulations. Journal of Abnormal Psychology, 97(2), 218-230.

Cooper, M. L., Russell, M., Skinner, J. B., \& Windle, M. (1992). Development and validation of a three-dimensional measure of drinking motives. Psychological Assessment, 4(2), 123-132.

Corbin, W. R., Farmer, N. M., \& Nolen-Hoekesma, S. (2013). Relations among stress, coping strategies, coping motives, alcohol consumption and related problems: a mediated moderation model. Addictive Behaviors, 38(4), 1912-9.

Cox, W. M., \& Klinger, E. (1988). A motivational model of alcohol use. Journal of Abnormal Psychology, 97(2), 168-180.

Crutzen, R., Kuntsche, E., \& Schelleman-Offermans, K. (2013). Drinking motives and drinking behavior over time: a full cross-lagged panel study among adults. Psychology of Addictive Behaviors, 27(1), 197-201.

Demartini, K. S., \& Carey, K. B. (2011). The role of anxiety sensitivity and drinking motives in predicting alcohol use : A critical review. Clinical Psychology Review, 31(1), 169-177. Retrieved from http://dx.doi.org/10.1016/j.cpr.2010.10.001

DiClemente, C. C., Bellino, L. E., \& Neavins, T. M. (1999). Motivation for change and alcoholism treatment. Alcohol Research \& Health: The Journal of the National Institute on Alcohol Abuse and Alcoholism, 23(2), 86-92.

Engels, R. C. M. E., Wiers, R., Lemmers, L., \& Overbeek, G. J. (2005). Drinking motives, alcohol expectancies, self-efficacy, and drinking patterns. Journal of Drug Education, 35(2), 147-66.

Faul, F., Erdfelder, E., Lang, A., \& Buchner, A. (2007). G* Power 3: A flexible statistical power analysis program for the social, behavioral, and biomedical sciences. Behavior Research Methods, 39(2), 175-191. 


\section{MOTIVES-RELATED FEEDBACK AND DRINKING TO COPE}

Galen, L. W., Henderson, M. J., \& Coovert, M. D. (2001). Alcohol expectancies and motives in a substance abusing male treatment sample. Drug and Alcohol Dependence, 62(3), 205-214.

George, W. H., Frone, M. R., Cooper, M. L., Russell, M., Skinner, J. B., \& Windle, M. (1995). A revised Alcohol Expectancy Questionnaire: Factor structure confirmation and invariance in a general population sample. Journal of Studies on Alcohol and Drugs, 56, 177-185.

Grant, V. V, Stewart, S. H., O’Connor, R. M., Blackwell, E., \& Conrod, P. J. (2007). Psychometric evaluation of the five-factor Modified Drinking Motives Questionnaire-Revised in undergraduates. Addictive Behaviors, 32(11), 2611-32.

Ham, L. S., Zamboanga, B. L., Bacon, A. K., \& Garcia, T. A. (2009). Drinking motives as mediators of social anxiety and hazardous drinking among college students. Cognitive Behaviour Therapy, 38(3), 113-145.

Hayes, A. F. (2009). Beyond Baron and Kenny: Statistical Mediation Analysis in the New Millennium. Communication Monographs, 76(4), 408-420.

Hecimovic, K., Barrett, S. P., Darredeau, C., \& Stewart, S. H. (2014). Cannabis use motives and personality risk factors. Addictive Behaviors, 39, 729-732.

Hu, L., \& Bentler, P. M. (1998). Fit indices in covariance structure modeling: Sensitivity to underparameterized model misspecification. Psychological Methods, 3(4), 424.

Hu, L., \& Bentler, P. M. (1999). Cutoff criteria for fit indexes in covariance structure analysis: Conventional criteria versus new alternatives. Structural Equation Modeling: A Multidisciplinary Journal, 6(1), 1-55.

Johnson, K., Mullin, J. L., Marshall, E. C., Bonn-Miller, M. O., \& Zvolensky, M. (2010). Exploring the mediational role of coping motives for marijuana use in terms of the relation between anxiety sensitivity and marijuana dependence. The American Journal on Addictions, 19(3), 277-282.

Kline, R. (2005). Principles and practice of structural equation modeling (2nd ed.). New York, NY: Guilford Press.

Kruse, M., Fromme, K., \& Corbin, W. (2005). Improving the accuracy of self-report measures of drinking: Disaggregating quantity and frequency indices of alcohol consumption. Alcoholism, Clinical and Experimental Research, 29(5).

Kuntsche, E., Knibbe, R., Engels, R., \& Gmel, G. (2007). Drinking motives as mediators of the link between alcohol expectancies and alcohol use among adolescents. Journal of Studies on Alcohol and Drugs, 68(1), 76-85.

Kushner, M. G., Abrams, K., Thuras, P., Hanson, K. L., Brekke, M., \& Sletten, S. (2005). Follow-up study of anxiety disorder and alcohol dependence in comorbid alcoholism treatment patients. Alcoholism: Clinical \& Experimental Research, 29(8), 1432-1443. 


\section{MOTIVES-RELATED FEEDBACK AND DRINKING TO COPE}

LaBrie, J. W., Huchting, K., Tawalbeh, S., Pedersen, E. R., Thompson, A. D., Shelesky, K., ... Neighbors, C. (2008). A randomized motivational enhancement prevention group reduces drinking and alcohol consequences in first-year college women. Psychology of Addictive Behaviors, 22(1), 149-155.

Meade, A. W., \& Craig, S. B. (2012). Identifying careless responses in survey data. Psychological Methods, 17(3), 437-55.

Mezquita, L., Stewart, S. H., Ibáñez, M. I., Ruipérez, M. A., Villa, H., Moya, J., \& Ortet, G. (2011). Drinking motives in clinical and general populations. European Addiction Research, $17(5), 250-261$.

Mitchell, H., Zvolensky, M. J., Marshall, E. C., Bonn-Miller, M. O., \& Vujanovic, A. A. (2007). Incremental validity of coping-oriented marijuana use motives in the prediction of affectbased psychological vulnerability. Journal of Psychopathology and Behavioral Assessment, 29(4), 277-288.

Mohr, C. D., Brannan, D., Wendt, S., Jacobs, L., Wright, R., \& Wang, M. (2013). Daily mooddrinking slopes as predictors: A new take on drinking motives and related outcomes. Psychology of Addictive Behaviors.

Moyer, A., Finney, J., Swearingen, C., \& Vergun, P. (2002). Brief interventions for alcohol problems: a meta-analytic review of controlled investigations in treatmen-seeking and nontreatment-seeking populations. Addiction, 97(3), 279-292.

Muthén, L., \& Muthén, B. (2011). Mplus User's Guide (Sixth Edit.). Los Angeles, CA: Muthén \& Muthén.

Neighbors, C., Lewis, M. A., Bergstrom, R. L., \& Larimer, M. E. (2006). Being controlled by normative influences: Self-determination as a moderator of a normative feedback alcohol intervention. Health Psychology, 25, 571-579.

Preacher, K. J., \& Hayes, A. F. (2008). Asymptotic and resampling strategies for assessing and comparing indirect effects in multiple mediator models. Behavior Research Methods, 40(3), 879-891.

Read, J. P., Wood, M. D., Kahler, C. W., Maddock, J. E., \& Palfai, T. P. (2003). Examining the role of drinking motives in college student alcohol use and problems. Psychology of Addictive Behaviors, 17(1), 13-23.

Rohsenow, D. J. (1983). Drinking habits and expectancies about alcohol's effects for self versus others. Journal of Consulting and Clinical Psychology, 51(5), 752-756.

Salemink, E., \& Wiers, R. W. (2014). Alcohol-related memory associations in positive and negative affect situations: Drinking motives, working memory capacity, and prospective drinking. Psychology of Addictive Behaviors, 28, 105-113. 


\section{MOTIVES-RELATED FEEDBACK AND DRINKING TO COPE}

Schelleman-Offermans, K., Kuntsche, E., \& Knibbe, R. a. (2011). Associations between drinking motives and changes in adolescents' alcohol consumption: a full cross-lagged panel study. Addiction, 106(7), 1270-8.

Simons, J. S., Gaher, R. M., Correia, C. J., Hansen, C. L., \& Christopher, M. S. (2005). An affective-motivational model of marijuana and alcohol problems among college students. Psychology of Addictive Behaviors, 19(3), 326-334.

Stephens, R. S., Roffman, R. A., Fearer, S. A., Williams, C., Picciano, J. F., \& Burke, R. S. (2004). The Marijuana Check-Up: Reaching users who are ambivalent about change. Addiction, 99, 1323-1332.

Stewart, S. H., Hall, E., Wilkie, H., \& Birch, C. (2002). Affective priming of alcohol schema in coping and enhancement motivated drinkers. Cognitive Behaviour Therapy, 31(2), 68-80.

Substance Abuse and Mental Heath Services Administration. (2012). The National Survey on Drug Use and Health. Office of Applied Statistics. Rockville, MD. Retrieved from http://www.oas.samhsa.gov/

Taylor, A. B., MacKinnon, D. P., \& Tein, J.-Y. (2007). Tests of the Three-Path Mediated Effect. Organizational Research Methods, 11(2), 241-269.

Tyne, K., Zamboanga, B. L., Ham, L. S., Olthuis, J. V., \& Pole, N. (2011). Drinking motives as mediators of the associations between alcohol expectancies and risky drinking behaviors among high school students. Cognitive Therapy and Research, 36(6), 756-767.

Vasilaki, E., Hosier, S., \& Cox, W. (2006). The efficacy of motivational interviewing as a brief intervention for excessive drinking: a meta-analytic review. Alcohol and Alcoholism.

Walker, D. D., Roffman, R. A., Stephens, R. S., Wakana, K., \& Berghuis, J. (2006). Motivational Enhancement Therapy for adolescent marijuana users: A preliminary randomized controlled trial. Journal of Consulting and Clinical Psychology, 74(3), 628-632.

White, H. R., \& LaBouvie, E. W. (1989). Towards the assessment of alcohol problem drinking. Journal of Studies on Alcohol, 50(1), 30-37.

Willem, L., Bijttebier, P., Claes, L., \& Uytterhaegen, A. (2012). Temperament and problematic alcohol use in adolescence: an examination of drinking motives as mediators. Journal of Psychopathology and Behavioral Assessment, 34(2), 282-292.

Windle, M., \& Windle, R. C. (1996). Coping strategies, drinking motives, and stressful life events among middle adolescents : Associations with emotional and behavioral problems and with academic functioning. Journal of Abnormal Psychology, 105(4), 551-560.

Windle, M., \& Windle, R. C. (2012). Testing the specificity between social anxiety disorder and drinking motives. Addictive Behaviors, 37(9), 1003-8. 


\section{MOTIVES-RELATED FEEDBACK AND DRINKING TO COPE}

Woicik, P. A., Stewart, S. H., Pihl, R. O., \& Conrod, P. J. (2009). The Substance Use Risk Profile Scale: a scale measuring traits linked to reinforcement-specific substance use profiles. Addictive Behaviors, 34(12), 1042-55. 
MOTIVES-RELATED FEEDBACK AND DRINKING TO COPE

Table 1. Descriptive Statistics for Goal 1 Measures

\begin{tabular}{lccccccc}
\hline & \multicolumn{3}{c}{ Baseline } & \multicolumn{2}{c}{ Follow-up } & \multicolumn{2}{c}{ Differences } \\
\hline & & Mean & SD & Mean & SD & Time x \\
Cond.
\end{tabular}

MFC $\mathrm{n}=87$; SFC $\mathrm{n}=83$

$* p<.05$

$* * p<.01$ 
MOTIVES-RELATED FEEDBACK AND DRINKING TO COPE

Table 2. Tests of Motives Moderation between the Intervention and Outcomes

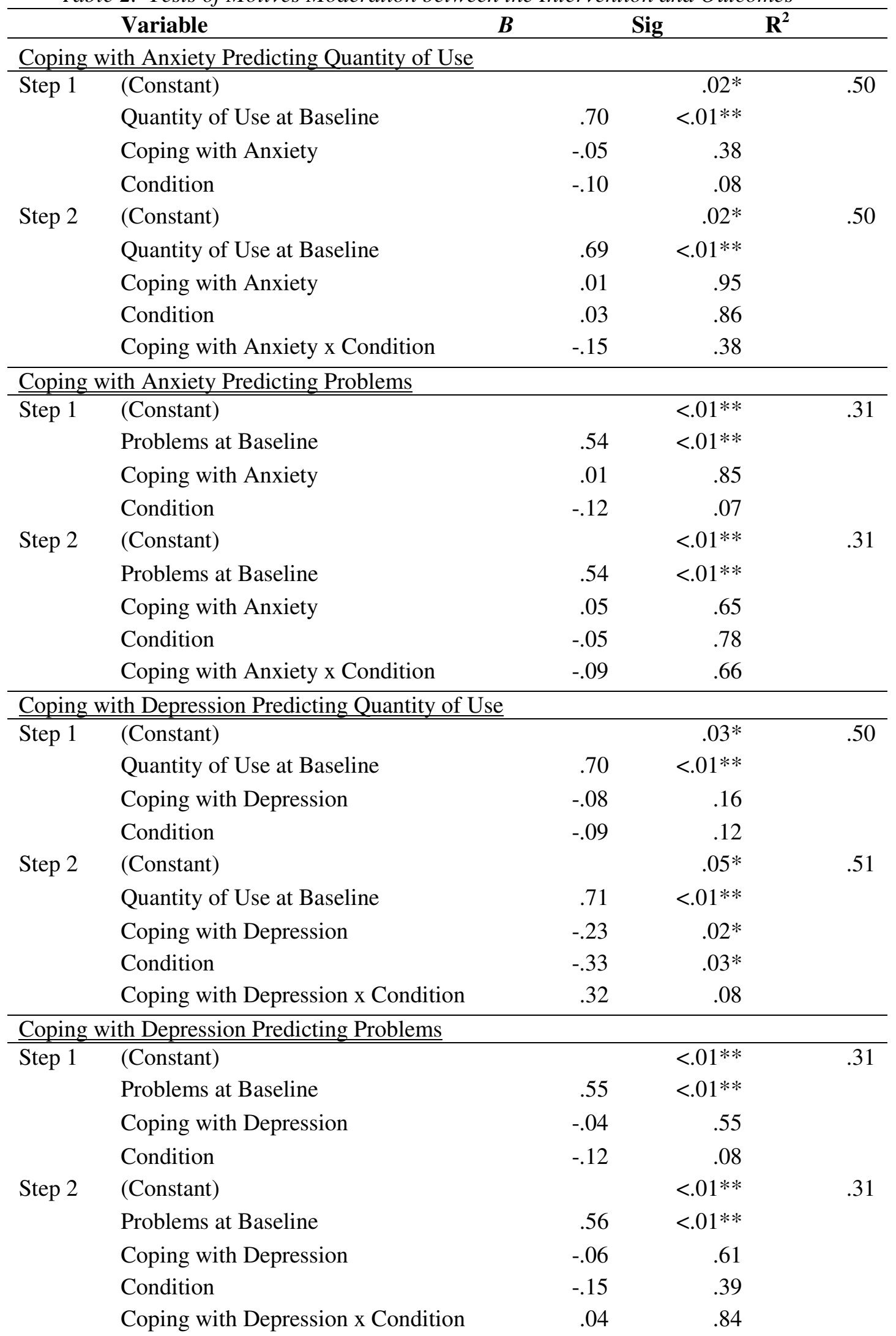


MOTIVES-RELATED FEEDBACK AND DRINKING TO COPE

Table 3. Descriptive Statistics and Correlations for Goal 2 Measures

\begin{tabular}{|c|c|c|c|c|c|c|c|c|c|c|c|c|}
\hline & $\begin{array}{c}\text { Mean } \\
\text { (SD) }\end{array}$ & 1. & 2. & 3. & 4. & 5. & 6. & 7. & 8. & 9. & 10. & 11. \\
\hline 1. Denial Coping & $\begin{array}{l}1.44 \\
(.64) \\
1.47\end{array}$ & 1 & & & & & & & & & & \\
\hline 2. Behavioral Disengagement Coping & $\begin{array}{l}(.57) \\
2.34\end{array}$ & $.52 * *$ & 1 & & & & & & & & & \\
\hline 3. Self-Blame Coping & $\begin{array}{l}(.84) \\
2.56\end{array}$ & $.31 * *$ & $.36 * *$ & 1 & & & & & & & & \\
\hline 4. Global Positive Expectancies & $\begin{array}{l}(.84) \\
3.58\end{array}$ & $.17 *$ & .12 & $.28 * *$ & 1 & & & & & & & \\
\hline 5. Tension Reduction Expectancies & $\begin{array}{l}(.90) \\
2.54\end{array}$ & .12 & .10 & $.27 * *$ & $.58 * *$ & 1 & & & & & & \\
\hline 6. Anxiety Sensitivity & $\begin{array}{l}(.55) \\
1.70\end{array}$ & $.31 * *$ & $.17^{*}$ & $.27 * *$ & .10 & .08 & 1 & & & & & \\
\hline 7. Hopelessness & $\begin{array}{l}(.46) \\
2.12\end{array}$ & $.20 * *$ & $.35^{* *}$ & $.38 * *$ & $.25 * *$ & $.36 * *$ & $.24 * *$ & 1 & & & & \\
\hline 8. Coping with Anxiety & $\begin{array}{l}(.86) \\
1.51\end{array}$ & $.32 * *$ & $.30 * *$ & $.39 * *$ & $.61 * *$ & $.47 * *$ & $.28 * *$ & $.30 * *$ & 1 & & & \\
\hline 9. Coping with Depression & $\begin{array}{c}(.66) \\
13.53\end{array}$ & $.35^{* *}$ & $.28 * *$ & $.32 * *$ & $.55^{* *}$ & $.44 * *$ & $.27 * *$ & $.41 * *$ & $.72 * *$ & 1 & & \\
\hline 10. Quantity of Alcohol Use & $\begin{array}{c}(8.82) \\
6.74\end{array}$ & -.13 & .10 & -.04 & .06 & .14 & $-.22 * *$ & .08 & .09 & .02 & 1 & \\
\hline 11. Alcohol Problems & $(5.22)$ & $.18^{*}$ & $24 * *$ & $.26 * *$ & $.29 * *$ & $.32 * *$ & .06 & $.25 * *$ & $.32 * *$ & $.27 * *$ & $.28 * *$ & 1 \\
\hline
\end{tabular}

$* p<.05 ; * * p<.01$ 
MOTIVES-RELATED FEEDBACK AND DRINKING TO COPE

Figure 1. Changes in Quantity of Alcohol Use Over Time

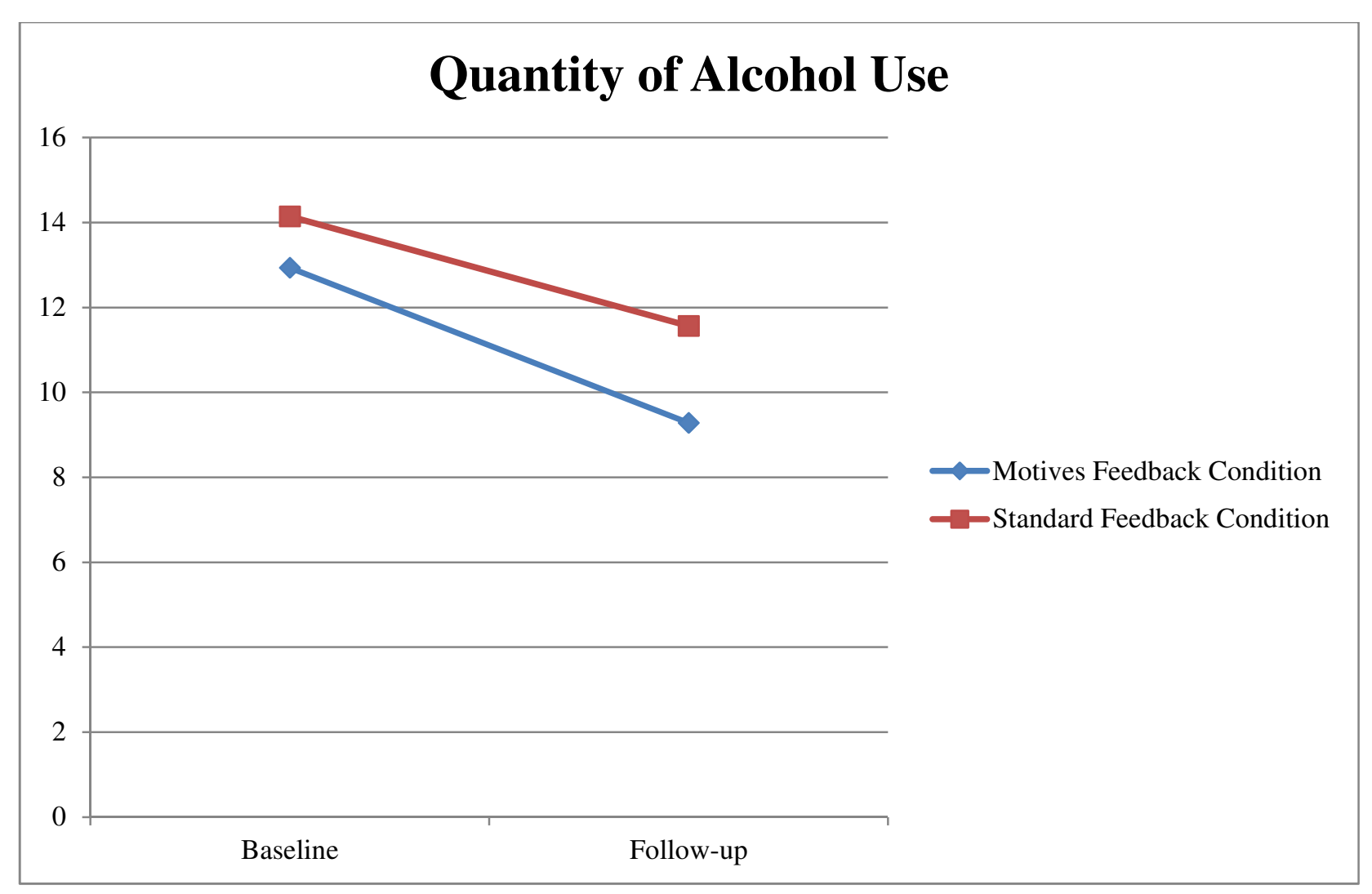


MOTIVES-RELATED FEEDBACK AND DRINKING TO COPE

Figure 2. Changes in Alcohol-Related Problems Over Time

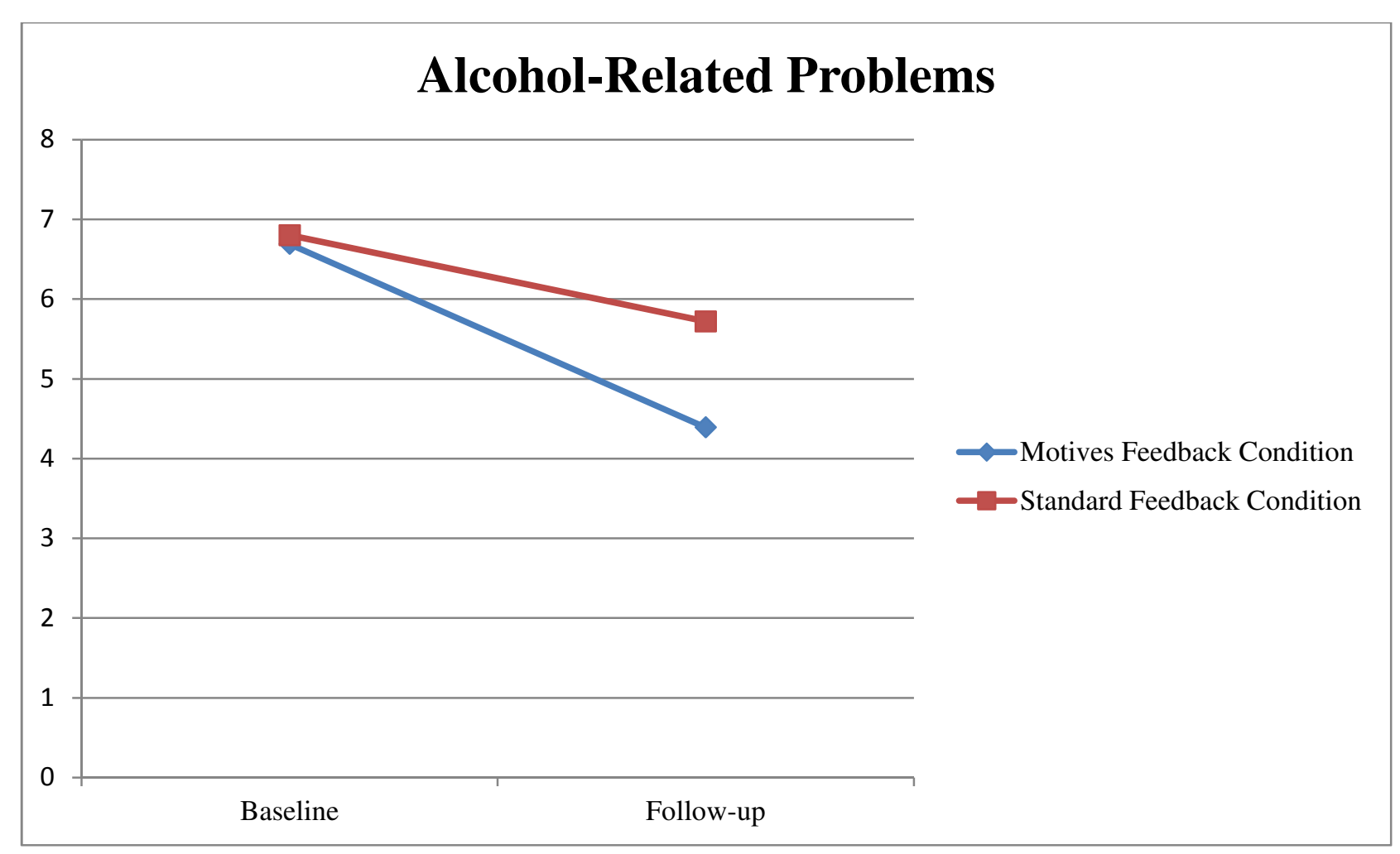




\section{MOTIVES-RELATED FEEDBACK AND DRINKING TO COPE}

Figure 3. Model of Alcohol Use Motivation

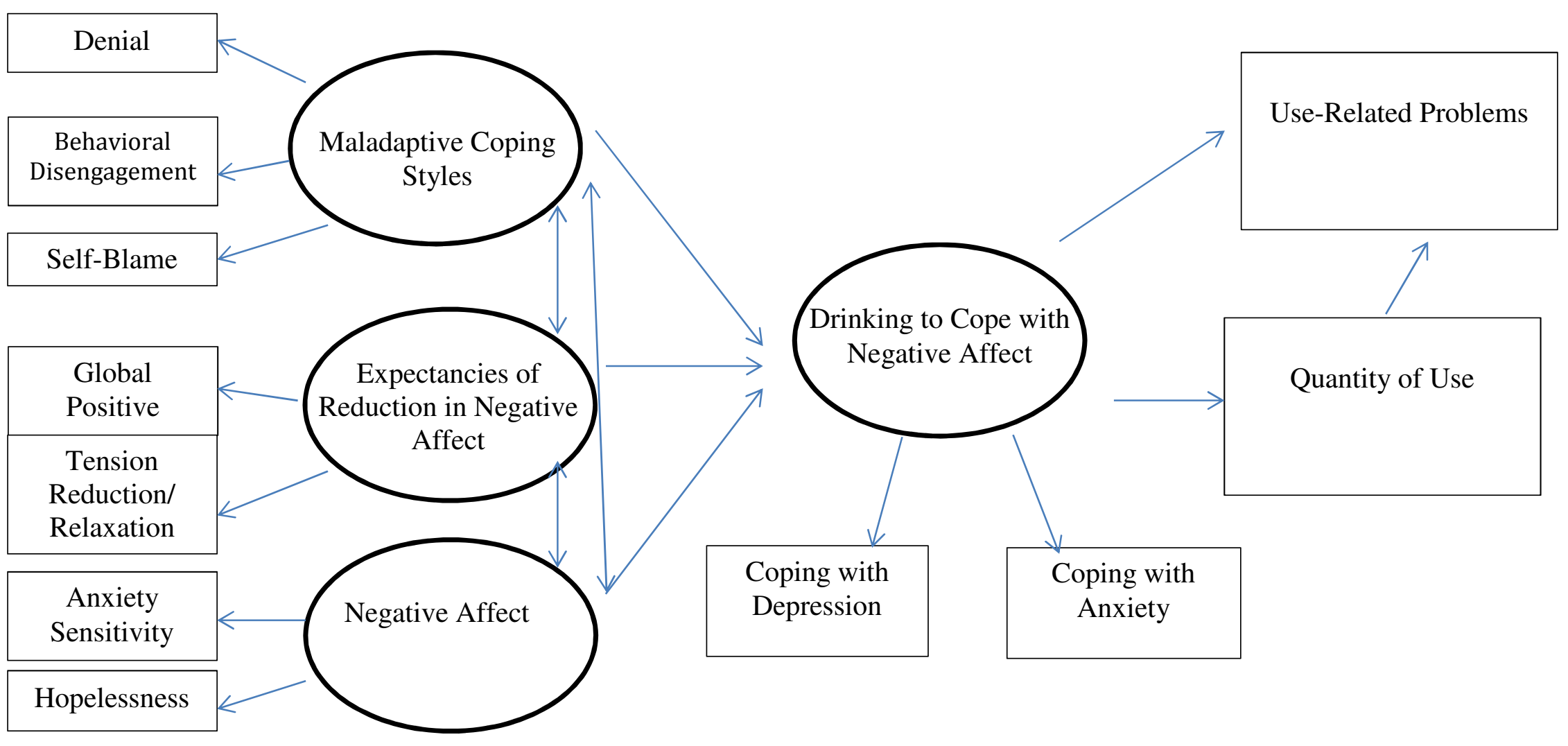




\section{MOTIVES-RELATED FEEDBACK AND DRINKING TO COPE}

Figure 4. Analyses Testing the Mediational Value of Change in Coping Motives

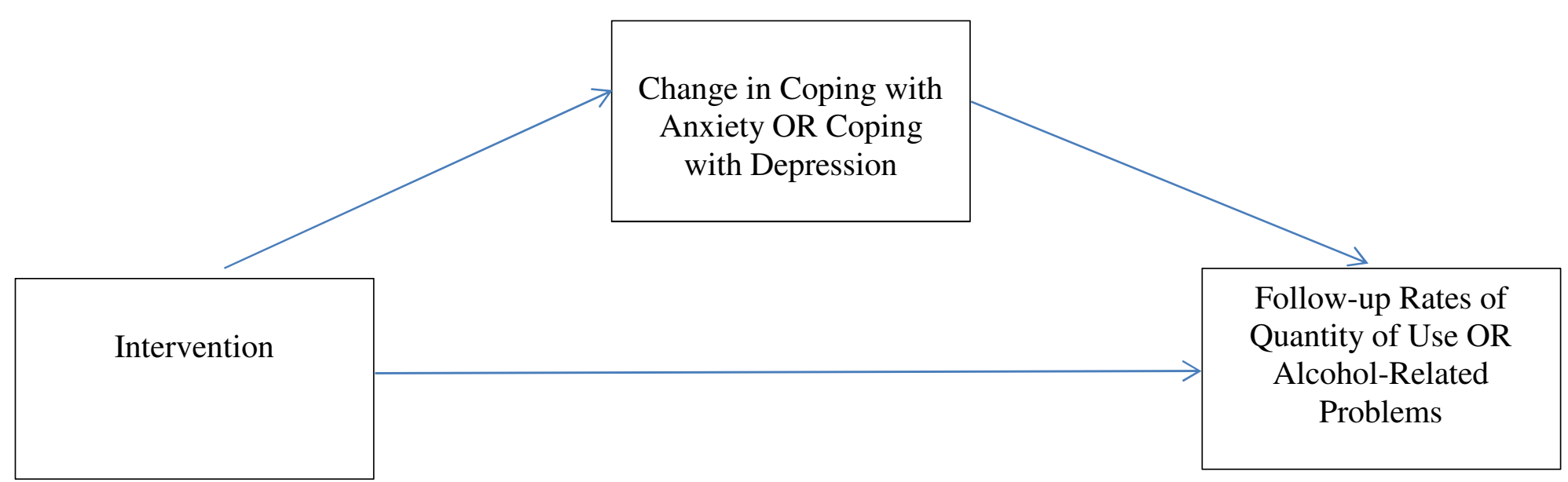




\section{MOTIVES-RELATED FEEDBACK AND DRINKING TO COPE}

Figure 5. Structrural Equation Modeling Results

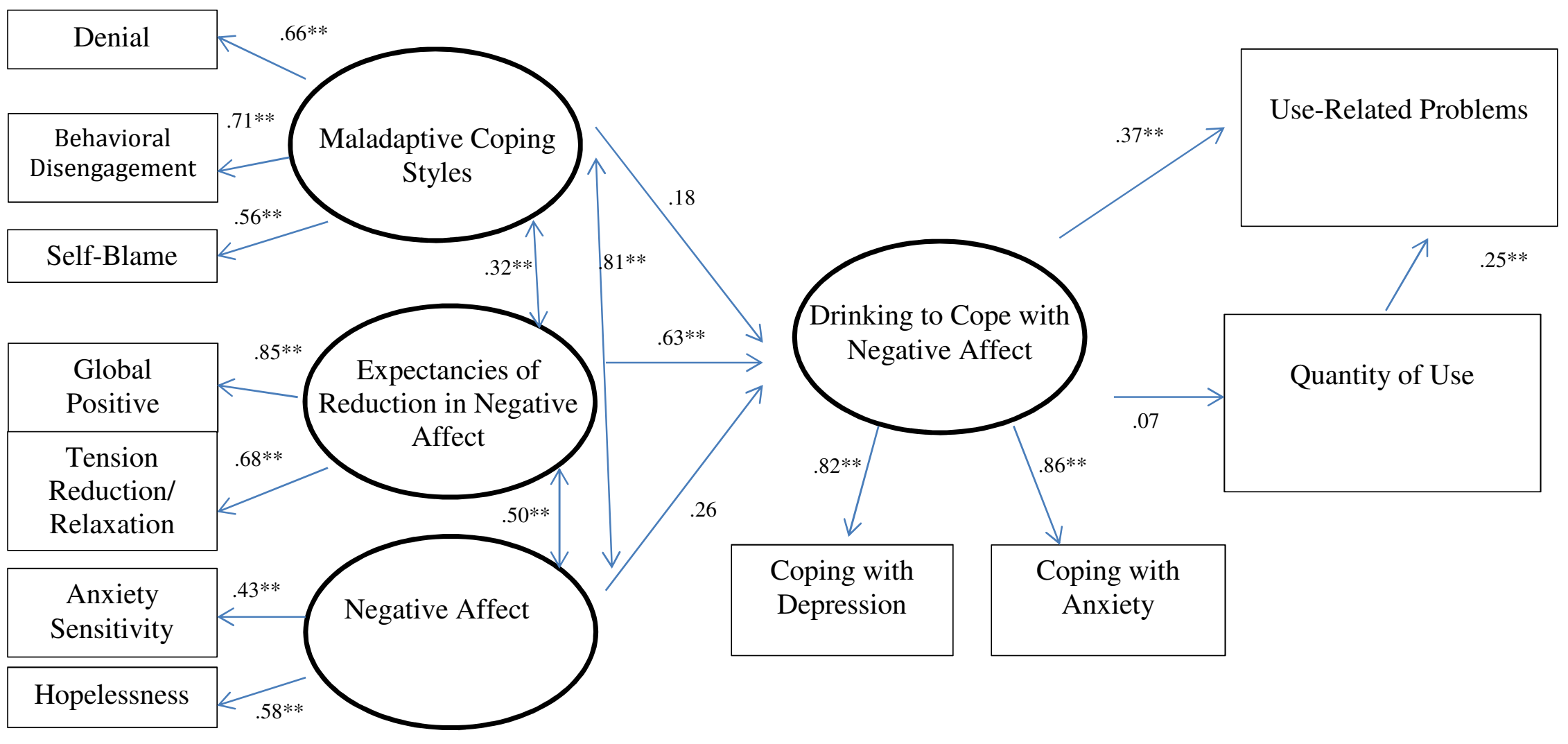


MOTIVES-RELATED FEEDBACK AND DRINKING TO COPE

Appendix A. Demographic Information

DEMOGRAPHICS

1) What is your age?

2) What is your gender?

Male

- Female

3) What is your race or ethnic background?

Alaska Native/Eskimo

_ Asian/Asian American

Black/African American

—_ Hawaiian/Pacific Islander

_ Hispanic/Latino

_ Native American/American Indian

_ White/Caucasian

_ Multi-Racial (explain)

_ Other (explain) 


\section{MODIFIED DMQ-R}

INSTRUCTIONS: Listed below are reasons people might be inclined to drink alcoholic beverages. Using the five-point scale below, decide how frequently your own drinking is motivated by each of the reasons listed.

YOU DRINK...

1. As a way to celebrate

2. To relax

3. Because I like the feeling

4. Because it is what most of my

4. friends do when we get together

5. To forget my worries

6. Because it is exciting

7. To be sociable

8. Because I feel more self-

. confident or sure of myself.

9. To get a high

10. Because it is customary on special occasions

11. Because it helps me when I am feeling nervous

12. Because it's fun

13. Because it makes a social

13. gathering more enjoyable

14. To cheer me up when I' $m$ in a bad mood

15. To be liked

16. To numb my pain

17. Because it helps me when I am feeling depressed

18. So that others won't kid me about not using

19. To reduce my anxiety

20. To stop me from dwelling on things

21. To turn off negative thoughts about myself

22. To help me feel more positive about things in my life

23. To stop me from feeling so hopeless about the future

24. Because my friends pressure me to use

25. To fit in with a group I like

26. Because it makes me feel good

27. To forget painful memories

28. So I won't feel left out

\begin{tabular}{|c|c|c|c|c|}
\hline $\begin{array}{l}\text { Almost } \\
\text { Never/ } \\
\text { Never }\end{array}$ & $\begin{array}{c}\text { Some of the } \\
\text { time }\end{array}$ & $\begin{array}{l}\text { Half of the } \\
\text { time }\end{array}$ & $\begin{array}{l}\text { Most of the } \\
\text { time }\end{array}$ & $\begin{array}{c}\text { Almost } \\
\text { Always/ } \\
\text { Always }\end{array}$ \\
\hline 1 & 2 & 3 & 4 & 5 \\
\hline 1 & 2 & 3 & 4 & 5 \\
\hline 1 & 2 & 3 & 4 & 5 \\
\hline 1 & 2 & 3 & 4 & 5 \\
\hline 1 & 2 & 3 & 4 & 5 \\
\hline 1 & 2 & 3 & 4 & 5 \\
\hline 1 & 2 & 3 & 4 & 5 \\
\hline 1 & 2 & 3 & 4 & 5 \\
\hline 1 & 2 & 3 & 4 & 5 \\
\hline 1 & 2 & 3 & 4 & 5 \\
\hline 1 & 2 & 3 & 4 & 5 \\
\hline 1 & 2 & 3 & 4 & 5 \\
\hline 1 & 2 & 3 & 4 & 5 \\
\hline 1 & 2 & 3 & 4 & 5 \\
\hline 1 & 2 & 3 & 4 & 5 \\
\hline 1 & 2 & 3 & 4 & 5 \\
\hline 1 & 2 & 3 & 4 & 5 \\
\hline 1 & 2 & 3 & 4 & 5 \\
\hline 1 & 2 & 3 & 4 & 5 \\
\hline 1 & 2 & 3 & 4 & 5 \\
\hline 1 & 2 & 3 & 4 & 5 \\
\hline 1 & 2 & 3 & 4 & 5 \\
\hline 1 & 2 & 3 & 4 & 5 \\
\hline 1 & 2 & 3 & 4 & 5 \\
\hline 1 & 2 & 3 & 4 & 5 \\
\hline 1 & 2 & 3 & 4 & 5 \\
\hline 1 & 2 & 3 & 4 & 5 \\
\hline 1 & 2 & 3 & 4 & 5 \\
\hline
\end{tabular}




\section{Appendix C. Risky Personality Profiles.}

\section{SURPS}

Instructions: Please indicate the extent to which you agree with the following statements

If you "STRONGLY DISAGREE", circle "1"

If you "DISAGREE", circle " 2 "

If you "AGREE", circle "3"

If you "STRONGLY AGREE", circle "4"

1. I am content

2. I often don't think things through before I speak

3. I would like to skydive

4. I am happy

5. I often involve myself in situations that I later regret

being involved in

Strongly

Disagree

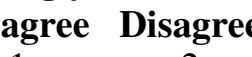

$1 \quad 2$

12

12

$1 \quad 2$

1

6. I enjoy new and exciting experiences even if they

are unconventional

7. I have faith that my future holds great promise

8. It's frightening to feel dizzy or faint

9. I like doing things that frighten me a little

10. It frightens me when feel my heart beat change

11. I usually act without stopping to think

12. I would like to learn how to drive a motorcycle

13. I feel proud of my accomplishments

14. I get scared when I'm too nervous

15. Generally, I am an impulsive person

16. I am interested in experience for its own sake even if

16. it is illegal

17. I feel that I'm a failure

18. I get scared when I experience unusual body

sensations

19. I would enjoy hiking long distances in wild and

19. uninhabited territory

20. I feel pleasant

21. It scares me when I'm unable to focus on a task

22. I feel I have to be manipulative to get what I want

23. I am very enthusiastic about my future 


\section{Appendix D: Situations of Use}

\section{IDS-42}

Instructions: The following are a number of situations or events in which some people drink heavily. Read each item carefully, and answer in terms of your own drinking over the past year.

If you "NEVER" drank heavily in that situation, circle " 1 "

If you "RARELY" drank heavily in that situation, circle " 2 "

If you "FREQUENTLY" drank heavily in that situation, circle "3"

If you "ALMOST ALWAYS" drank heavily in that situation, circle "4"

1. When I felt that I had let myself down

3. When I felt confident and relaxed

7. When I was out with friends and they stopped by a bar

7. for a drink

8. When I wanted to heighten my sexual enjoyment

1. When I was relaxed with a good friend and wanted to

have a good time

12. When I was afraid things weren't going to work out

14. When everything was going well

18. When I was at a party and other people were drinking

19. When I wanted to feel closer to someone I liked

22. When I was angry at the way things had turned out

24. When I felt satisfied with something I had done

28. When I was in a restaurant and the people with me ordered drinks

\begin{tabular}{cccc||} 
Never & Rarely & $\begin{array}{c}\text { Frequen } \\
\text { tly }\end{array}$ & $\begin{array}{c}\text { Almost } \\
\text { Always }\end{array}$ \\
1 & 2 & 3 & 4 \\
1 & 2 & 3 & 4 \\
1 & 2 & 3 & 4 \\
1 & 2 & 3 & 4 \\
1 & 2 & 3 & 4 \\
1 & 2 & 3 & 4 \\
1 & 2 & 3 & 4 \\
1 & 2 & 3 & 4 \\
1 & 2 & 3 & 4 \\
1 & 2 & 3 & 4 \\
1 & 2 & 3 & 4 \\
1 & 2 & 3 & 4 \\
1 & 2 & 3 & 4 \\
1 & 2 & 3 & 4 \\
1 & 2 & 3 & 4 \\
1 & 2 & 3 & 4 \\
1 & 2 & 3 & 4 \\
1 & 2 & 3 & 4
\end{tabular}

29. When I was out with friends "on the town" and wanted

29. to increase my enjoyment

31. When I felt confused about what I should do

33. When something good happened and I felt like

celebrating

37. When I met a friend and he/she suggested that we have a drink together

38. When I wanted to celebrate with a friend

41. When I was enjoying myself at a party and wanted to feel even better 
Appendix E. Drinking Companions and Locations

1. Please indicate the locations that you usually consume alcohol and the companions that you typically drink with:

\begin{tabular}{|l|l|l|}
\hline & \multicolumn{1}{|c|}{ No } & \multicolumn{1}{|c|}{ Yes } \\
\hline At home & & \\
\hline At a friend's home & & \\
\hline At parties & & \\
\hline At bars & & \\
\hline Alone & & \\
\hline With family & & \\
\hline With same-sex friends & & \\
\hline With mixed-sex friends & & \\
\hline
\end{tabular}


MOTIVES-RELATED FEEDBACK AND DRINKING TO COPE

Appendix F. Norms.

\section{DESCRIPTIVE NORMS}

In these next questions, we're asking you to make some guesses about how other people use alcohol. For many of the questions, you may not know the answer, but please just give your best estimate or guess for each question.

Overall, what percentage of people your age do you think have ever used alcohol? __\%

Overall, what percentage of people your age do you think regularly use alcohol? _ $\%$

What percent of your close friends have ever used alcohol? _ $\%$

What percent of your close friends use alcohol regularly? _ $\%$

INJUNCTIVE NORMS

How much do you think the average student your age approves of...

\begin{tabular}{|c|c|c|c|c|c|c|c|}
\hline & $\begin{array}{c}\text { Strongly } \\
\text { Disapprove }\end{array}$ & $\begin{array}{c}\text { Moderately } \\
\text { Disapprove }\end{array}$ & $\begin{array}{c}\text { Somewhat } \\
\text { Disapprove }\end{array}$ & $\begin{array}{c}\text { Neither } \\
\text { Approve } \\
\text { nor } \\
\text { Disapprove }\end{array}$ & $\begin{array}{c}\text { Somewhat } \\
\text { Approve }\end{array}$ & $\begin{array}{c}\text { Moderately } \\
\text { Approve }\end{array}$ & $\begin{array}{c}\text { Strongly } \\
\text { Approve }\end{array}$ \\
\hline $\begin{array}{c}\text { Trying alcohol once or } \\
\text { twice }\end{array}$ & $\mathbf{1}$ & $\mathbf{2}$ & $\mathbf{3}$ & $\mathbf{4}$ & $\mathbf{5}$ & $\mathbf{6}$ & $\mathbf{7}$ \\
\hline $\begin{array}{c}\text { Drinking alcohol } \\
\text { occasionally }\end{array}$ & $\mathbf{1}$ & $\mathbf{2}$ & $\mathbf{3}$ & $\mathbf{4}$ & $\mathbf{5}$ & $\mathbf{6}$ & $\mathbf{7}$ \\
\hline $\begin{array}{c}\text { Drinking alcohol } \\
\text { regularly }\end{array}$ & $\mathbf{1}$ & $\mathbf{2}$ & $\mathbf{3}$ & $\mathbf{4}$ & $\mathbf{5}$ & $\mathbf{6}$ & $\mathbf{7}$ \\
\hline
\end{tabular}

How do you think your close friends feel (or would feel) about you...

\begin{tabular}{|c|c|c|c|c|c|c|c|}
\hline & $\begin{array}{c}\text { Strongly } \\
\text { Disapprove }\end{array}$ & $\begin{array}{c}\text { Moderately } \\
\text { Disapprove }\end{array}$ & $\begin{array}{c}\text { Somewhat } \\
\text { Disapprove }\end{array}$ & $\begin{array}{c}\text { Neither } \\
\text { Approve } \\
\text { nor } \\
\text { Disapprove }\end{array}$ & $\begin{array}{c}\text { Somewhat } \\
\text { Approve }\end{array}$ & $\begin{array}{c}\text { Moderately } \\
\text { Approve }\end{array}$ & $\begin{array}{c}\text { Strongly } \\
\text { Approve }\end{array}$ \\
\hline $\begin{array}{c}\text { Trying alcohol once or } \\
\text { twice }\end{array}$ & $\mathbf{1}$ & $\mathbf{2}$ & $\mathbf{3}$ & $\mathbf{4}$ & $\mathbf{5}$ & $\mathbf{6}$ & $\mathbf{7}$ \\
\hline $\begin{array}{c}\text { Drinking alcohol } \\
\text { occasionally }\end{array}$ & $\mathbf{1}$ & $\mathbf{2}$ & $\mathbf{3}$ & $\mathbf{4}$ & $\mathbf{5}$ & $\mathbf{6}$ & $\mathbf{7}$ \\
\hline $\begin{array}{c}\text { Drinking alcohol } \\
\text { regularly }\end{array}$ & $\mathbf{1}$ & $\mathbf{2}$ & $\mathbf{3}$ & $\mathbf{4}$ & $\mathbf{5}$ & $\mathbf{6}$ & $\mathbf{7}$ \\
\hline
\end{tabular}




\section{MOTIVES-RELATED FEEDBACK AND DRINKING TO COPE}

\section{Appendix G: Coping Style}

\section{BRIEF COPE}

Instruction: We are interested in how people respond when they confront difficult or stressful events in their lives. There are lots of ways to try to deal with stress. This questionnaire asks you to indicate what you generally do and feel, when you experience stressful events.

Obviously, different events bring out somewhat different responses, but think about what you usually do when you are under a lot of stress. Then respond to each of the following items by circling one number on your answer sheet for each, using the response choices listed just below.

Please try to respond to each item separately in your mind from each other item. Choose your answers thoughtfully, and make your answers as true FOR YOU as you can. Please answer every item. There are no "right" or "wrong" answers, so choose the most accurate answer for YOU--not what you think "most people" would say or do.

\begin{tabular}{|c|c|c|c|c|}
\hline When I am under a lot of stress, usually... & $\begin{array}{l}\text { Don't do } \\
\text { this at } \\
\text { all }\end{array}$ & $\begin{array}{l}\text { Do this a } \\
\text { little bit }\end{array}$ & $\begin{array}{l}\text { Do this a } \\
\text { medium } \\
\text { amount }\end{array}$ & $\begin{array}{l}\text { Do this a } \\
\text { lot }\end{array}$ \\
\hline $\begin{array}{l}\text { 1. I turn to work or other activities to take my mind off } \\
\text { things. }\end{array}$ & 1 & 2 & 3 & 4 \\
\hline $\begin{array}{l}\text { 2. I concentrate my efforts on doing something about the } \\
\text { situation I'm in. }\end{array}$ & 1 & 2 & 3 & 4 \\
\hline 3. I've been saying to myself "this isn't real." & 1 & 2 & 3 & 4 \\
\hline $\begin{array}{l}\text { 4. I've been using alcohol or other drugs to make myself } \\
\text { feel better. }\end{array}$ & 1 & 2 & 3 & 4 \\
\hline 5. I've been getting emotional support from others. & 1 & 2 & 3 & 4 \\
\hline 6. I've been giving up trying to deal with it. & 1 & 2 & 3 & 4 \\
\hline $\begin{array}{l}\text { 7. I've been taking action to try to make the situation } \\
\text { better. }\end{array}$ & 1 & 2 & 3 & 4 \\
\hline 8. I've been refusing to believe that it has happened. & 1 & 2 & 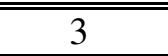 & 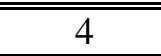 \\
\hline 10. I've been getting help and advice from other people. & 1 & 2 & 3 & 4 \\
\hline $\begin{array}{l}\text { 11. I've been using alcohol or other drugs to help me get } \\
\text { through it. }\end{array}$ & 1 & 2 & 3 & 4 \\
\hline 13. I've been criticizing myself. & 1 & 2 & 3 & 4 \\
\hline $\begin{array}{l}\text { 14. I've been trying to come up with a strategy about what } \\
\text { to do. }\end{array}$ & 1 & 2 & 3 & 4 \\
\hline $\begin{array}{l}\text { 15. I've been getting comfort and understanding from } \\
\text { someone. }\end{array}$ & 1 & 2 & 3 & 4 \\
\hline 16. I've been giving up the attempt to cope. & 1 & 2 & 3 & 4 \\
\hline $\begin{array}{l}\text { 19. I've been doing something to think about it less, such } \\
\text { as going to movies, watching TV, reading, daydreaming, } \\
\text { sleeping, or shopping. }\end{array}$ & 1 & 2 & 3 & 4 \\
\hline $\begin{array}{l}\text { 20. I've been accepting the reality of the fact that it has } \\
\text { happened. }\end{array}$ & 1 & 2 & 3 & 4 \\
\hline $\begin{array}{l}\text { 23. I've been trying to get advice or help from other } \\
\text { people about what to do. }\end{array}$ & 1 & 2 & 3 & 4 \\
\hline 24. I've been learning to live with it. & 1 & 2 & 3 & 4 \\
\hline 25. I've been thinking hard about what steps to take. & 1 & 2 & 3 & 4 \\
\hline 26. I've been blaming myself for things that happened. & 1 & 2 & 3 & 4 \\
\hline
\end{tabular}




\section{AEQ-3}

The following questions contain statements about the effects of alcohol. I want you to respond according to your own personal thoughts, feelings and beliefs about alcohol now. I am interested in what you think about alcohol, regardless of what other people might think.

\begin{tabular}{|c|c|c|c|c|c|c|}
\hline & \multicolumn{3}{|c|}{ Disagree } & \multicolumn{3}{|c|}{ Agree } \\
\hline & $\begin{array}{l}\text { Disagree } \\
\text { Strongly }\end{array}$ & $\begin{array}{l}\text { Moderat } \\
\text { ely }\end{array}$ & $\begin{array}{l}\text { Disagree } \\
\text { Slightly }\end{array}$ & $\begin{array}{l}\text { Agree } \\
\text { Slightly }\end{array}$ & $\begin{array}{l}\text { Moderat } \\
\text { ely }\end{array}$ & $\begin{array}{c}\text { Agree } \\
\text { Strongly }\end{array}$ \\
\hline $\begin{array}{l}\text { 2. Alcohol lowers muscle tension in } \\
\text { my body }\end{array}$ & 1 & 2 & 3 & 4 & 5 & 6 \\
\hline A few drinks make me feel less shy & 1 & 2 & 3 & 4 & 5 & 6 \\
\hline $\begin{array}{l}\text { Alcohol helps me fall asleep more } \\
\text { easily }\end{array}$ & 1 & 2 & 3 & 4 & 5 & 6 \\
\hline $\begin{array}{l}\text { Drinking makes the future seem } \\
\text { brighter to me }\end{array}$ & 1 & 2 & 3 & 4 & 5 & 6 \\
\hline $\begin{array}{l}\text { Alcohol can act as an anesthetic for } \\
\text { me, that is, it can stop pain }\end{array}$ & 1 & 2 & 3 & 4 & 5 & 6 \\
\hline 13. Drinking makes me feel good & 1 & 2 & 3 & 4 & 5 & 6 \\
\hline $\begin{array}{l}\text { Some alcohol has a pleasant, } \\
\text { cleansing, tingly taste to me }\end{array}$ & 1 & 2 & 3 & 4 & 5 & 6 \\
\hline 17. Alcohol seems like magic to me & 1 & 2 & 3 & 4 & 5 & 6 \\
\hline $\begin{array}{l}\text { When I'm drinking, it is easier to } \\
\text { open up and express my feelings }\end{array}$ & 1 & 2 & 3 & 4 & 5 & 6 \\
\hline $\begin{array}{l}\text { Drinking adds a certain warmth and } \\
\text { me friendliness to social occasions for } \\
\text { me }\end{array}$ & 1 & 2 & 3 & 4 & 5 & 6 \\
\hline $\begin{array}{l}\text { If I'm feeling tied down or } \\
\text { frustrated, a few drinks make me } \\
\text { feel better }\end{array}$ & 1 & 2 & 3 & 4 & 5 & 6 \\
\hline $\begin{array}{l}\text { Having a few drinks is a nice way } \\
\text { 4. for me to celebrate special } \\
\text { occasions }\end{array}$ & 1 & 2 & 3 & 4 & 5 & 6 \\
\hline $\begin{array}{l}\text { Alcohol makes me worry less } \\
\text { Drinking is pleasurable because it's }\end{array}$ & 1 & 2 & 3 & 4 & 5 & $\begin{array}{l}6 \\
6\end{array}$ \\
\hline $\begin{array}{l}\text { enjoyable for me to join in with } \\
\text { people who are enjoying } \\
\text { themselves }\end{array}$ & 1 & 2 & 3 & 4 & 5 & \\
\hline $\begin{array}{l}\text { I feel more physically coordinated } \\
\text { after I drink }\end{array}$ & 1 & 2 & 3 & 4 & 5 & 6 \\
\hline 4. Alcohol helps me sleep better & 1 & 2 & 3 & 4 & 5 & 6 \\
\hline $\begin{array}{l}\text { Drinking gives me more confidence } \\
\text { in myself }\end{array}$ & 1 & 2 & 3 & 4 & 5 & 6 \\
\hline $\begin{array}{l}\text { A few drinks make it easier for me } \\
\text { to talk to people }\end{array}$ & 1 & 2 & 3 & 4 & 5 & 6 \\
\hline $\begin{array}{l}\text { If I have a couple of drinks, it is } \\
\text { easier for me to express my feelings }\end{array}$ & 1 & 2 & 3 & 4 & 5 & 6 \\
\hline 40. Alcohol makes me more interesting & 1 & 2 & 3 & 4 & 5 & 6 \\
\hline
\end{tabular}


MOTIVES-RELATED FEEDBACK AND DRINKING TO COPE

Appendix I. Stage Of Change, Importance and Confidence Rulers.

1. Which statement best represents how you feel right now about your alcohol use?

(1) I'm basically satisfied with my use of alcohol and do not plan to change it.

(2) I'm thinking about stopping or reducing my use of alcohol, but I don't think I'll begin doing that in the next 30 days.

(3) I think I will stop or reduce my use of alcohol sometime in the next 30 days.

(4) Sometime within the past 6 months I stopped or reduced my level of alcohol use and I have not returned to my previous level of use.

(5) More than 6 months ago, I stopped or reduced my level of alcohol use and I have not returned to my previous level of use.

2. On a scale of 0 - 10 with 0 being not at all important and 10 being the most important, how important is it for you to make a change in your alcohol use?

3. On a scale of 0 - 10 with 0 being not at all confident and 10 being the most confident, how confident are you that you can make a change in your alcohol use? 
Appendix J. Alcohol Use.

\section{DDQ-R (Daily Drinking Questionnaire-Revised)}

\section{IN THE CALENDAR BELOW, PLEASE FILL-IN YOUR DRINKING RATE AND TIME DRINKING DURING A TYPICAL WEEK IN THE LAST 30 DAYS.}

First, think of a typical week in the last 30 days you. Try to remember as accurately as you can, how much and for how long you typically drank in a week during that one month period?

For each day of the week in the calendar below, fill in the number of standard drinks typically consumed on that day in the upper box and the typical number of hours you drank that day in the lower box.

Convert unusual quantity drinks to standard drink units

$(12 \mathrm{oz}$ beer $=5 \mathrm{oz}$. wine $=1$ 1/2 oz. liquor $)$ for example, $40 \mathrm{oz}$ beer $=3.5$ drinks

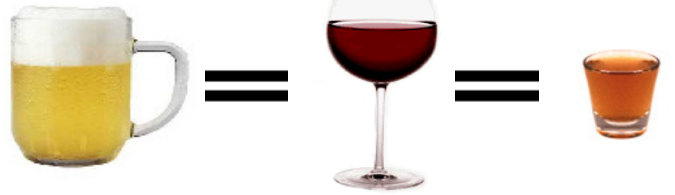

\begin{tabular}{|l|l|l|l|l|l|l|l|}
\hline & Monday & Tuesday & Wednesday & Thursday & Friday & Saturday & Sunday \\
\hline Number of Drinks & & & & & & & \\
\hline $\begin{array}{l}\text { Number of Hours } \\
\text { Drinking }\end{array}$ & & & & & & & \\
\hline
\end{tabular}

IN THE CALENDAR BELOW, PLEASE FILL-IN YOUR DRINKING RATE AND TIME DRINKING DURING YOUR HEAVIEST DRINKING WEEK IN THE LAST 30 DAYS.

First, think of your heaviest drinking week in the last 30 days. Try to remember as accurately as you can, how much and for how long did you drink during your heaviest drinking week in that one month period?

For each day of the week in the calendar below, fill in the number of standard drinks consumed on that day in the upper box and the number of hours you drank that day in the lower box.

Convert unusual quantity drinks to standard drink units

$(12 \mathrm{oz}$ beer $=5 \mathrm{oz}$. wine $=1 \mathrm{l} / 2 \mathrm{oz}$. liquor $)$ for example, $40 \mathrm{oz}$ beer $=3.5$ drinks

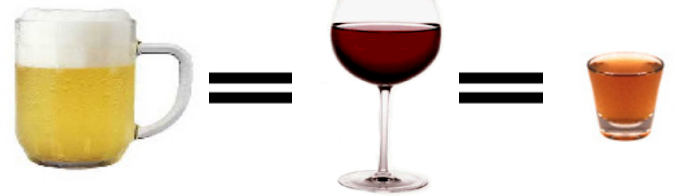

\begin{tabular}{|l|l|l|l|l|l|l|l|}
\hline & Monday & Tuesday & Wednesday & Thursday & Friday & Saturday & Sunday \\
\hline Number of Drinks & & & & & & & \\
\hline $\begin{array}{l}\text { Number of Hours } \\
\text { Drinking }\end{array}$ & & & & & & & \\
\hline
\end{tabular}




\section{MOTIVES-RELATED FEEDBACK AND DRINKING TO COPE}

\section{Appendix K. Other Drug Use.}

1. During the past $\mathbf{3 0}$ days, on how many days have you used marijuana?

2. During the past $\mathbf{3 0}$ days, on how many days have you used any other drugs, such as: cocaine or crack, heroin or other opiates, inhalants, hallucinogen, sedative, stimulant, or any other drug?

days

If you answered 0 days to 6, please SKIP to the next section

Please describe: 
Appendix L. Alcohol Problems.

\section{RAPI}

Instructions: Different things happen to people while they are drinking ALCOHOL or because of their ALCOHOL drinking. Several of these things are listed below. Indicate how many times each of these things happened to you WITHIN THE LAST MONTH.

1. Not able to do your homework or study for a test

2. Got into fights with other people (friends, relatives, strangers)

3. Missed out on other things because you spent too much money on alcohol

4. Went to work or school high or drunk

5. Caused shame or embarrassment to someone

6. Neglected your responsibilities

7. Relatives avoided you

8. Felt that you needed more alcohol than you used

8. to in order to get the same effect Tried to control your drinking (tried to drink only

9. at certain times of the day or in certain places, that is, tried to change your pattern of drinking)

10. Had withdrawal symptoms, that is, felt sick

because you stopped or cut down on drinking

11. Noticed a change in your personality

12. Felt that you had a problem with alcohol

13. Missed a day (or part of a day) of school or work

14. Wanted to stop drinking but couldn't

15. Suddenly found yourself in a place that you could

15. not remember getting to

16. Passed out or fainted suddenly

17. Had a fight, argument or bad feeling with a friend

18. Had a fight, argument or bad feeling with a

18. family member

19. Kept drinking when you promised yourself not to

20. Felt that you were going crazy

21. Had a bad time

22. Felt physically or psychologically dependent on alcohol

\begin{tabular}{|c|c|c|c|}
\hline None & 1-2 times & 3-5 times & $\begin{array}{l}\text { More } \\
\text { than } 5 \\
\text { times }\end{array}$ \\
\hline 0 & 1 & 2 & 3 \\
\hline 0 & 1 & 2 & 3 \\
\hline 0 & 1 & 2 & 3 \\
\hline 0 & 1 & 2 & 3 \\
\hline 0 & 1 & 2 & 3 \\
\hline 0 & 1 & 2 & 3 \\
\hline 0 & 1 & 2 & 3 \\
\hline 0 & 1 & 2 & 3 \\
\hline 0 & 1 & 2 & 3 \\
\hline 0 & 1 & 2 & 3 \\
\hline 0 & 1 & 2 & 3 \\
\hline 0 & 1 & 2 & 3 \\
\hline 0 & 1 & 2 & 3 \\
\hline 0 & 1 & 2 & 3 \\
\hline 0 & 1 & 2 & 3 \\
\hline 0 & 1 & 2 & 3 \\
\hline 0 & 1 & 2 & 3 \\
\hline 0 & 1 & 2 & 3 \\
\hline 0 & 1 & 2 & 3 \\
\hline 0 & 1 & 2 & 3 \\
\hline 0 & 1 & 2 & 3 \\
\hline 0 & 1 & 2 & 3 \\
\hline 0 & 1 & 2 & 3 \\
\hline
\end{tabular}

23. Was told by a friend, neighbor or relative to stop or cut down drinking 


\section{Appendix M. Manipulation Check.}

The purpose of these questions is to ensure that you received the feedback that was given. Not all participants were given enough information to answer all of these questions. Please answer to the best of your ability.

1. What motive for alcohol use was discussed as being associated with many negative outcomes, such as a higher rate of problems associated with alcohol use?
a. Enhancement
b. Social
c. Coping
d. Conformity
e. This information was not given in the feedback report

2. According to the feedback report, if you drink more than 10 standard drinks in one sitting then you are considered an alcoholic.
a. True
b. False
c. This information was not given in the feedback report

3. Drinking to cope is associated with lower rates of drinking.
a. True
b. False
c. This information was not given in the feedback report

4. Most Virginia Tech students drink less than 5 drinks per week.
a. True
b. False
c. This information was not given in the feedback report

5. About $95 \%$ of college students nationwide drink alcohol.
a. True
b. False
c. This information was not given in the feedback report 


\section{MOTIVES-RELATED FEEDBACK AND DRINKING TO COPE}

Appendix N. Description of Study.

\section{Alcohol Feedback Project}

This study is designed to understand the usefulness of different types of feedback related to alcohol use. The study will have two components: an initial lab-based survey with feedback and a follow-up online survey. You must be at least 18 years old, be willing to participate in both sections of the study, and drink at least two days per week for the past two months (or at least 8 of the past 60 days). Two SONA credits will be offered for the lab-based survey with feedback, and one will be offered for the follow-up online survey for a total of four potential SONA credits. Additionally, participants will be entered to win one of twenty-three \$25 gift cards for participation after completion of the follow-up survey. 


\section{MOTIVES-RELATED FEEDBACK AND DRINKING TO COPE}

\section{Appendix O. Verbal Consent for Screening and Screening Questions.}

"This study is designed to determine the usefulness of different types of feedback related to alcohol use. The study will have two components: an initial lab-based survey with feedback and a follow-up online survey.

Are you willing to participate in screening for this study?"

\section{IF YES}

"Are you at least 18 years of age?

Have you consumed alcohol at least two days per week on average for the past two months?

Are you willing to participate in both sections of the study?"

\section{IF NO}

“Thank you for your time." 


\title{
VIRGINIA POLYTECHNIC INSTITUTE AND STATE UNIVERSITY Informed Consent for Participants in Research Projects Involving Human Subjects
}

\author{
Title of Project: $\quad$ The Impact of Motives-Related Feedback on Drinking to Cope Among College \\ Students \\ Investigator(s): $\quad$ Claire E. Blevins, M.S. and Robert S. Stephens, PhD.
}

\section{Purpose of this Research}

You are invited to participate in a research study designed to understand the usefulness of different types of feedback related to alcohol use. The study will have two components: an initial labbased survey with feedback and a follow-up online survey two months later. Approximately 154 undergraduate students, who are at least 18 years old, are willing to participate in a follow-up survey, and have consumed alcohol at least two days per week in the last two months will be recruited to participate in this study.

The purpose of this consent form is to give you the information you will need to help you decide whether to be in the study or not. Please read the form carefully. If you have questions about the purpose of the research, what we would ask you to do, the possible risks and benefits, your rights as a volunteer, and anything else about the research or this form that is not clear, you can contact the research staff using the contact information listed at the end of this form. When we have answered all your questions, you can decide if you want to be in the study or not. This process is called "informed consent." We can print a copy of this form for your own records, or we can email you the form if you prefer.

\section{Procedures}

This study consists of questionnaire items assessing demographic characteristics, use of alcohol and other substances, outcomes associated with use, and other individual characteristics. The questions will ask you about your reasons for using alcohol, personality risk factors for using alcohol, situations in which you usually drink, your beliefs about alcohol use among other individuals, coping style, expectancies associated with drinking, motivation for change, and any problems or consequences you may have experienced as a result of use. You will complete all of these questions in a lab setting. It is expected that these questions will take approximately one hour to complete. After completing the questions, you will be given a pamphlet of personalized feedback. After reviewing the pamphlet, you will be asked several questions to ascertain your understanding of the information. Approximately two months later, you will be asked to take another questionnaire comprised of many of the same questions. This assessment will be taken online at your own convenience and in a location of you choosing.

\section{Risks}

Few risks are involved with participation in this study. If there are any questions that make you feel uncomfortable, you may refuse to answer those questions or discontinue your participation in the study without penalty. All information from this study will be kept confidential. If there were to be an unlikely breach of confidentiality, there may be a risk of others knowing that you have taken part in an illegal activity (i.e. underage drinking) if you are under 21 years of age. In order to mitigate this risk, your survey responses will be kept separate from any identifying information and will be instead identified by a four-digit code. 


\section{Benefits}

No promise or guarantees of benefits have been made to encourage you to participate. You may benefit by learning how psychological research is conducted.

\section{Extent of Confidentiality}

The information you provide will be kept strictly confidential. A code number will be assigned to the data you provide. The researchers will be the only people that have access to the data and at no time will the researchers release the results of the study to anyone in a way that identifies you or even that you participated in the study. Once data collection is completed, analyzed, and thus no longer needed, it will be destroyed in order to further protect your confidentiality. It is possible that the Institutional Review Board (IRB) may review this study's collected data for auditing purposes. The IRB is responsible for the oversight of the protection of human subjects involved in research.

\section{Compensation}

Students in psychology courses will be eligible to receive up to three research credits for participating in this study: two after completing the initial session and one after completing the follow-up assessment two months later. Additionally, you will be entered to win one of twenty-three \$25 gift cards for participation to be draw after completion of the follow-up survey (approximate odds of winning are 1 in 5). It is not necessary for you to participate in research to receive research credits. All psychology courses that offer benefits for receiving research credits also offer alternate ways to obtain these credits other than participating in research. These alternate ways are described in the syllabus for each course.

\section{Freedom to Withdraw}

If you wish to stop participating in the study at any time, you may do so without any penalty. To withdraw, you may simply contact the experimenter to express that you want to withdraw and any data you have provided will be destroyed. You may also choose not to answer specific questions without penalty.

\section{Participant's Responsibilities}

I voluntarily agree to participate in the research study. I have the following responsibilities:

I will be responsible for completing questionnaires that ask about my perceptions of consequences possibly associated with depression or anxiety and the risks of using marijuana in different situations. I will answer the questions honestly.

\section{Participant's Permission}

I have read the Consent Form and conditions of this project. I have had all my questions answered. I hereby acknowledge the above and give my voluntary consent: 


\section{MOTIVES-RELATED FEEDBACK AND DRINKING TO COPE}

Should I have any pertinent questions about this research or its conduct, and research subjects' rights, and whom to contact in the event of a research related injury, I may contact.

Claire E. Blevins $\quad$ Telephone (919) 323-6357 email: claireb9@vt.edu Investigator

Robert S. Stephens, PhD. $\quad$ Telephone (540) 231-6304 email: stephens@vt.edu Primary Investigator and Faculty Advisor

David Harrison, PhD. Telephone (540) 231-4422 email: dwh@vt.edu Chair, Human Subjects Committee

Dr. David Moore $\quad$ Telephone (540) 231-4491 email: moored@vt.edu Chair, Virginia Tech Institutional Review 


\section{Personal Feedback Report}

\section{Here's what we learned about your alcohol use....}

$>$ During the last 60 days, on average, you used alcohol on days per week.

$>$ Of college students across the country, about $80 \%$ use alcohol.

$>$ Here's how often other Virginia Tech students your age used alcohol in a week:

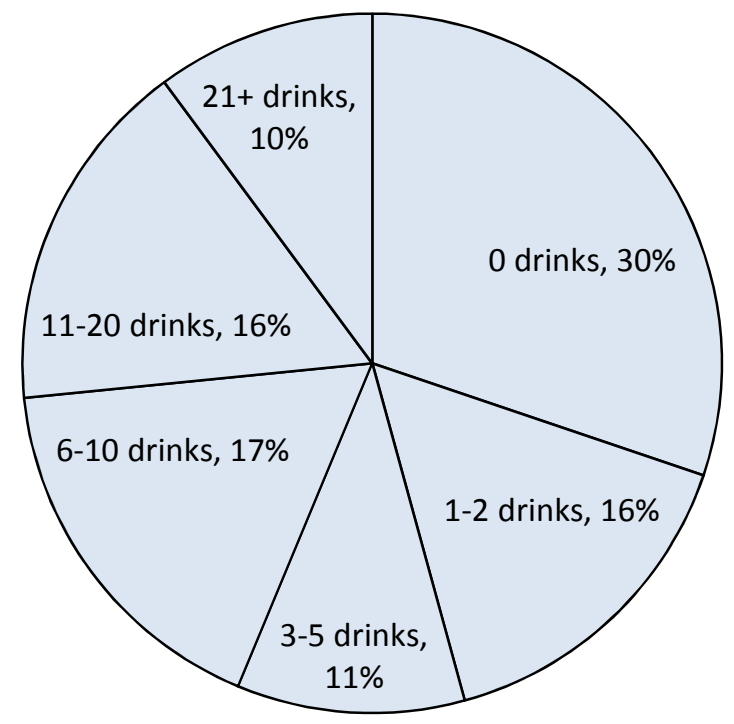

$>$ Most undergrads think students use more alcohol than they really do. It turns out that $30 \%$ of VT students don't drink on the average week. Most VT students drink less than 5 drinks on an average week. 


\section{Alcohol use can lead to consequences. These are}

the consequences that you experienced recently

1. You were not able to do your homework or study for a test

2. You got into fights with other people

3. You missed out on other things because you spent too much money on alcohol

4. You went to work or school high or drunk

5. You caused shame or embarrassment to someone

6. You neglected your responsibilities

7. Relatives avoided you

8. You felt that you needed more alcohol than you used to in order to get the same effect

9. You tried to control your drinking

10. You had withdrawal symptoms, that is, felt sick because you stopped or cut down on drinking

11. You noticed a change in your personality

12. You felt that you had a problem with alcohol

13. You missed a day (or part of a day) of school or work

14. You wanted to stop drinking but couldn't

15. You suddenly found yourself in a place that you could not remember getting to

16. You passed out or fainted suddenly

17. You had a fight, argument or bad feeling with a friend

18. You had a fight, argument or bad feeling with a family member

19. You kept drinking when you promised yourself not to

20. You felt you were going crazy

21. You had a bad time

22. You felt physically or psychologically dependent on alcohol

23. You were told by a friend, neighbor or relative to stop or cut down drinking

You reported of 23 red flags.

What do you think about the consequences that you have experienced? Do you think you're at risk for developing a problem with alcohol? 
How much alcohol is too much? Again, it depends on many factors. Current research indicates that people who average three or more standard drinks per day have a much higher risk of health and social problems. For some people, however, even 1-2 drinks per day would be too many. Certain health problems (such as liver disease) make even moderate drinking unsafe. Some people find that they are unable to drink moderately and having even one or two drinks leads to more drinks and intoxication. The World Health Organization recommends that adult men drink no more than 2 drinks per day and adult women drink no more than 1 drink per day. They also recommend not drinking every day. 


\section{Personal Feedback Report}

\section{Here's what we learned about your alcohol use....}

$>$ During the last 60 days, on average, you used alcohol on days per week.

$>$ Of college students across the country, about $80 \%$ use alcohol.

$>$ Here's how often other Virginia Tech students your age used alcohol in a week:

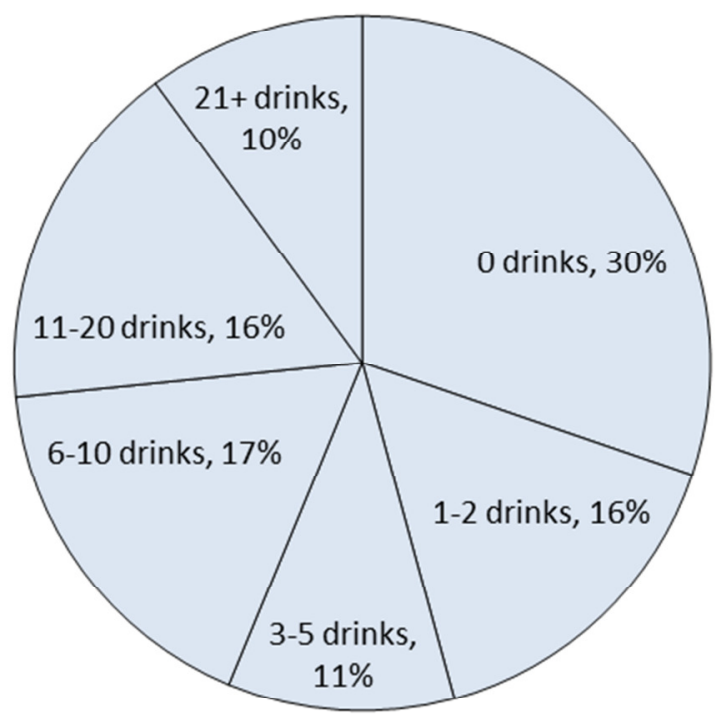

$>$ Most undergrads think students use more alcohol than they really do. It turns out that $30 \%$ of VT students don't drink on the average week. Most VT students drink less than 5 drinks on an average week. 


\section{Alcohol use can lead to consequences. These are}

the consequences that you experienced recently

1. You were not able to do your homework or study for a test

2. You got into fights with other people

3. You missed out on other things because you spent too much money on alcohol

4. You went to work or school high or drunk

5. You caused shame or embarrassment to someone

6. You neglected your responsibilities

7. Relatives avoided you

8. You felt that you needed more alcohol than you used to in order to get the same effect

9. You tried to control your drinking

10. You had withdrawal symptoms, that is, felt sick because you stopped or cut down on drinking

11. You noticed a change in your personality

12. You felt that you had a problem with alcohol

13. You missed a day (or part of a day) of school or work

14. You wanted to stop drinking but couldn't

15. You suddenly found yourself in a place that you could not remember getting to

16. You passed out or fainted suddenly

17. You had a fight, argument or bad feeling with a friend

18. You had a fight, argument or bad feeling with a family member

19. You kept drinking when you promised yourself not to

20. You felt you were going crazy

21. You had a bad time

22. You felt physically or psychologically dependent on alcohol

23. You were told by a friend, neighbor or relative to stop or cut down drinking

\section{You reported} of 23 red flags.

What do you think about the consequences that you have experienced? Do you think you're at risk for developing a problem with alcohol? 
How much alcohol is too much? Again, it depends on many factors. Current research indicates that people who average three or more standard drinks per day have a much higher risk of health and social problems. For some people, however, even 1-2 drinks per day would be too many. Certain health problems (such as liver disease) make even moderate drinking unsafe. Some people find that they are unable to drink moderately and having even one or two drinks leads to more drinks and intoxication. The World Health Organization recommends that adult men drink no more than 2 drinks per day and adult women drink no more than 1 drink per day. They also recommend not drinking every day.

\section{Reasons or motives for alcohol use can give us} information on who might be at risk for experiencing alcohol problems. Individuals who use alcohol to cope with negative emotions are most at risk for negative consequences.

$\checkmark$ You reported that you used alcohol for the following coping motives: To relax Because I feel more self-confident or sure of myself Because it helps me when I am feeling nervous To reduce my anxiety To forget my worries To cheer me up when I'm in a bad mood To numb my pain Because it helps me when I am feeling depressed To stop me from dwelling on things To turn off negative thoughts about myself To help me feel more positive about things in my life To stop me from feeling so hopeless about the future To forget painful memories

Do any of your responses concern you? What do you think about your motives for use? 
If any of the above were checked, here are some things to consider:

$\checkmark$ Other people who drink alcohol to cope tend to have more negative consequences associated with their alcohol use such as:

$\circ$ Problems in their relationships

D Difficulties with school or work performance.

$\checkmark$ Those who drink to cope with negative emotions are more likely to have a diagnosis of an alcohol use disorder.

$\checkmark$ Drinking to cope is associated with higher rates of drinking.

$\checkmark$ People who drink to cope are more likely to drink alone and when they are upset.

\section{Here are some alternate coping strategies that don't involve drinking alcohol:}

$\checkmark$ Actions

- Avoid or escape from the situation

$\circ$ Put off deciding to drink for $\mathbf{3 0}$ minutes

$\circ$ Do something distracting

Thoughts

$\circ$ Challenge unhealthy or unhelpful thoughts

- Give yourself a pep talk

$\circ$ Remind yourself of your reasons for cutting down your use

$\circ$ Visualize yourself as a lighter drinker-happy, healthy, and in control of our life

$\circ$ Picture the long-term effects from cutting down your drinking

$\checkmark$ Lifestyle

$\circ$ Exercise regularly

- Practice relaxation or meditation

- Take up a new hobby or try an old one

- Develop a routine for your day

- Prioritize sleep

- Reward yourself from cutting down your drinking

- Remove alcohol from your room

- Spend time in places where alcohol is not prevalent

- Spend time with friends who don't drink or don't drink heavily 